\title{
Moralizing mental states: The role of trait self-control and control perceptions
}

\author{
Alexa Weiss ${ }^{1}$, Matthias Forstmann ${ }^{2}, \&$ Pascal Burgmer ${ }^{3}$ \\ ${ }^{1}$ Bielefeld University, Germany \\ ${ }^{2}$ University of Zurich, Switzerland \\ ${ }^{3}$ University of Kent, United Kingdom
}

Accepted version before copy-editing, Cognition: March 8, 2021

Word count: 13,595

Declarations of interest: none

Corresponding Author:

Alexa Weiss

Bielefeld University

Fakultät für Psychologie und Sportwissenschaft

Abteilung für Psychologie

Postfach 100131

D-33501 Bielefeld

Germany

Phone: +49 (0)521 1064456

E-mail: alexa.weiss@uni-bielefeld.de 


\title{
SELF-CONTROL AND MORALIZATION OF MENTAL STATES
}

\begin{abstract}
Which attributes of a person contribute to their tendency to moralize others' thoughts? Adopting an individual-difference approach to moral cognition, eight studies $(N=2,033)$ investigated how people's ability for self-control shapes their moral reactions to others' mental states. Specifically, Studies $1 \mathrm{a}-2 \mathrm{~b}$ found positive predictive effects of trait self-control (TSC) on the moralization (e.g., blaming) of another person's fantasies about different immoral behaviors. While ruling out alternative explanations, they furthermore supported the mediating role of ascribing targets control over their mental states. Studies 3a-3b provided correlational evidence of the perceived ability to control one's own mental states as a mechanism in the relationship between TSC and ascriptions of control to others. Studies $4 a-4 b$ followed a causal-chain experimental approach: A manipulation of participants' self-perceived ability to control their emotions impacted their control ascriptions to others over their immoral mental states (Study 4a), and targets perceived as high (vs. low) in control over their immoral mental states elicited stronger moralizing reactions. Taken together, the present studies elucidate why people moralize others' purely mental states, even in the absence of overt behavior. More broadly, they advance our knowledge about the role of individual differences, particularly in self-control, in moral cognition.
\end{abstract}

Keywords: Moral judgment; Moralization; Mental states; Trait self-control; Free will; Blame 


\section{SELF-CONTROL AND MORALIZATION OF MENTAL STATES}

Imagine a friend confesses that she would like to cheat on her husband with an attractive acquaintance, or you overhear your colleague saying that he wishes for his rival to fail at an important project. What would you think of their thoughts and feelings? And how would these insights into their mental states affect your perception of your friend and colleague? In the present research, we investigate individual differences in people's ability for self-control as an antecedent to the moralization of such immoral mental states. Even though trait self-control has been identified as an important interindividual difference variable in the domain of immoral and deviant behavior, its relation to moral judgment, and its role in moral cognition more generally, remains unclear.

\section{The Morality of Mental States}

Research suggests that people frequently experience immoral or outright violent thoughts (Kenrick, 2011). According to consequentialist philosophical positions, malicious thoughts do not have moral value in themselves, but they do to the degree that they may lead individuals to commit harmful acts (see Adams, 1976). In many legal systems, thoughts and wishes proper are not regulated by law, and for most offenses, even planning them is not illegal. Indeed, recent psychological research found that fictitious harm done to others is condemned less than the same harm actually committed (Sabo \& Giner-Sorolla, 2017; see also Guglielmo \& Malle, 2019).

Yet, mental states contribute to the degree to which behaviors are morally condemned and punished (Cushman, 2008). For example, a vast literature documents that whether a target foresees and desires the harmful consequences of their behavior influences the degree to which they will be blamed for them, and how much people will desire to punish them (e.g., Alicke, 2000; Cushman, 2008). Furthermore, someone who behaves immorally out of an emotional state such as anger will be blamed less (Pizarro et al., 2003). In contrast, when the decision to carry 


\section{SELF-CONTROL AND MORALIZATION OF MENTAL STATES}

out an immoral behavior was quick, but not driven by emotional impulsivity, the actor is blamed strongly, because observers will infer low ambivalence regarding the immoral behavior (Critcher et al., 2013; see also Morewedge et al., 2014).

Such findings are in line with a person-centered account of moral judgment (Pizarro \& Tannenbaum, 2011; Uhlmann et al., 2015): People primarily seek information about others' moral character, not about their behaviors per se. Therefore, moral judgments of an act are strongly shaped by those aspects that are most diagnostic of the target's underlying character, rather than the act's mere consequences (Uhlmann et al., 2015). Seemingly harmless acts may thus receive surprisingly harsh judgments (Pizarro \& Tannenbaum, 2011). As a striking example, people behaving in a way that enables them to benefit from others' misfortunes are perceived as blameworthy and immoral, even though they do not actually do anything to bring about that misfortune (Inbar et al., 2012). For example, if a target invests money in bonds that will rise in value in the case of a natural disaster—which he cannot control—, observers will infer a "wicked desire" for the latter to occur, and therefore condemn his investment decision.

Thus far, however, only little research has directly investigated moral reactions to purely mental states. A character-based approach implies that even without any overt behavior, certain fantasies, desires, or emotions should cast a negative light on an individual's character, and hence be morally condemned. Research supports this prediction: Targets' (situationally inappropriate) affective displays provoke negative impressions, and lead observers to doubt that the target shares their moral values (Ames \& Johar, 2009; Szczurek et al., 2012). Moreover, even in the absence of any communication on the target's part, learning about their mental states can provoke moral reactions in observers (Sabo \& Giner-Sorolla, 2017). For example, targets who 


\section{SELF-CONTROL AND MORALIZATION OF MENTAL STATES}

experience hedonic pleasure from causing, or even from merely learning about, another's harm (e.g., the murder of a colleague) are perceived as immoral and evil (Gromet et al., 2016).

\section{Antecedents of the Moralization of Mental States: The Case of Control}

Yet, to date, there remain many questions around under which conditions people moralize purely mental states such as affective reactions, desires, and thoughts. Specifically, we know little about the antecedents and interindividual differences that may shape this tendency. Extensive research on immoral behavior, however, documents that for ascriptions of blame, control is central. The more control an actor has over the harmful consequences of their actions, or more generally over a norm-violating event, the more they are blamed for them (Alicke, 2000; Cushman, 2008; Malle et al., 2014). Similarly, intentionality, which indicates that a behavior is controllable, was found to be critical for the extent of moral blame that people assign to others, and also for judging a behavior as wrong or impermissible (Cushman, 2008; Malle et al., 2014; Malle \& Knobe, 1997; Monroe \& Malle, 2017). Additional research has drawn a connection between belief in free will, or perceptions of a target's free choice, and harsher moral judgment (e.g., Martin et al., 2017; Monroe et al., 2017; Shariff et al., 2014). Thus, when people perceive a target's norm-violating mental state to be under voluntary control, they should (a) judge that mental state as more morally wrong, and (b) blame the target more strongly. Following a personcentered account, they should (c) also draw more negative inferences about the target's moral character.

Indeed, seminal research by Cohen and Rozin (2001) provided initial insights into the role of control perceptions in the moralization of mental states: In a number of studies, Jews condemned immoral mental contents, such as fantasizing about an extramarital affair or disliking one's parents, less strongly than did Protestant Christians. These religious groups also differed in 


\section{SELF-CONTROL AND MORALIZATION OF MENTAL STATES}

their agreement with statements that mental states (vs. behavior) are indicative of a person's character. Interreligious differences in a "model of mind" emerged as well: Protestants judged immoral mental contents as more likely to be acted upon and as being subject to greater voluntary control than did Jews. Even though results were not unequivocal across studies, this work provides initial evidence that control might play a role in moralizing mental content. More recently, Cusimano and Goodwin (2019) systematically investigated variations in lay people's perceptions of the controllability of mental states using a large array of stimuli. They found that people ascribe a moderate degree of both controllability and intentionality to mental states such as desires, beliefs, or evaluations (Cusimano \& Goodwin, 2019), with meaningful variation between different kinds of mental states. Whereas the general focus of that work was on control ascriptions and therefore employed largely morally "neutral" mental states (e.g., believing that one did well on an exam), control and intentionality ascriptions predicted perceptions of targets being responsible or blameworthy for immoral mental states, and to what degree targets' mental state spoke to their character. For example, a White father's perceived ability to stop feeling angry about his daughter having a Black boyfriend predicted to what degree participants deemed him blameworthy and inferred bad character (Cusimano \& Goodwin, 2019). These studies provide additional correlational evidence that control ascriptions shape the moralization of mental states.

Drawing on these and earlier findings, the present research investigates a novel interindividual difference contributing to the moralization of mental states. Specifically, individuals with greater abilities for self-control might extend their (self-related) control perceptions to others' mental states, with important consequences for moral reasoning.

\section{Self-Control and Morality}




\section{SELF-CONTROL AND MORALIZATION OF MENTAL STATES}

The ability to exert self-control is related to success in virtually all domains of life, ranging from academic achievement to more satisfying relationships and greater subjective wellbeing (Tangney et al., 2004). Self-control has further been conceptualized as the "moral muscle" that determines whether we choose vices or virtues (Baumeister \& Exline, 1999; see also Baumeister \& Alghamdi, 2015; Fishbach \& Woolley, 2015; Gottfredson \& Hirschi, 1990; Hofmann et al., 2018). Indeed, measures of trait self-control (TSC) negatively predict different kinds of self-reported and observed deviant behavior, for example driving under the influence, physical assault, or academic dishonesty (e.g., Bolin, 2004; Tittle et al., 2003). Beyond research on TSC, temporarily impaired self-control has been linked to aggression and cheating (Denson et al., 2012; Gino et al., 2011; Mead et al., 2009).

While the effects of self-control abilities on behavioral deviance have been extensively documented, there is a striking lack of research on its role in moral cognition (Baumeister \& Alghamdi, 2015). Conceivably, highly disciplined individuals may have less understanding for other people's moral pitfalls. Importantly, would such a plausible relation between TSC and moralization extend to purely mental states, such as immoral thoughts, emotions, and desires?

\section{Self-Control and Moralization of Mental States}

The answer to this question is not straightforward. After all, highly disciplined individuals might be more concerned about what others $d o$, rather than what they think. They might thus consider immoral mental contents relatively unproblematic, and judge others rather

mildly when learning about their deviant thoughts or feelings — as long as these are not put into action. Indeed, theorizing and empirical research in the domain of self-control has long strongly focused on behavioral control (i.e., inhibition) of undesired impulses (e.g., Baumeister \& Exline, 1999; Baumeister et al., 2007; Hofmann et al., 2009). Restraining their behavior themselves even 


\section{SELF-CONTROL AND MORALIZATION OF MENTAL STATES}

in the face of strong temptations might raise the expectation in high-TSC individuals that others will similarly show impeccable behavior irrespective of their immoral inclinations.

Despite this emphasis on behavior, theorizing on self-control also addresses internal responses. According to Baumeister and colleagues (1994), controlling one's actions, but also one's thoughts, emotions, and impulses are important domains of self-control (see also Inzlicht et al., 2015). Process models of self-control emphasize the role of controlling corresponding mental states (e.g., Inzlicht \& Berkman, 2015): Self-control conflicts arise from the activation of a conflicting higher order goal, often associated "with a person's values and virtues," in the face of desire (Hofmann \& Kotabe, 2015, p. 623; Hofmann, Baumeister, et al., 2012). Upon detecting this conflict, exerting self-control comprises the suppression of undesired thoughts and the regulation of unwanted affect or desires (e.g., Inzlicht \& Legault, 2014; de Ridder et al., 2018). For example, people may direct their attention to desirable alternative mental content or engage in cognitive reappraisal, preventing extensive cognitive elaboration (Hofmann, Schmeichel, \& Baddeley, 2012; see also Duckworth et al, 2016; Hare et al., 2009). Arguably, individuals with high dispositional self-control ability are particularly good at downregulating response conflicts (e.g., Gillebaart \& de Ridder, 2015; Gillebaart et al., 2016), and they report experiencing weaker desires (Hofmann, Baumeister, et al., 2012). Higher self-reported TSC predicts less (anticipated) anger about imagined events, and weaker malevolent and fractious inclinations, such as the desire to vent (Tangney et al., 2004). A recent neuroimaging study found evidence that TSC was associated with some indicators of sustained and successful negative emotion down-regulation (Paschke et al., 2016). These insights are also reflected in current developments in the measurement of trait self-control which integrate multiple strategies and dimensions relating to 


\section{SELF-CONTROL AND MORALIZATION OF MENTAL STATES}

mental control beyond behavioral inhibition and impulse control (e.g., reappraisal; attentional control; Katzir et al., 2021; Nilsen et al., 2020).

Importantly, the ability for emotion-regulation seems to tie in with a sense that one is able to do so (Gross \& John, 2003). Similarly, behavioral self-control (i.e., performance) relates to self-perceptions of one's current abilities (Inzlicht \& Berkman, 2015). Thus, people appear to have insight into their abilities for behavioral and mental control. In addition, a large body of research finds social judgments to be heavily anchored in egocentric knowledge (e.g., Epley et al., 2004; Krueger \& Clement, 1994; Ross et al., 1977). Hence, to the degree that they perceive themselves to have control over their own mental states (e.g., are aware that they can regulate their emotions via reappraisal), high-TSC individuals should as well perceive others' immoral mental states as subject to voluntary control. Consequently, we hypothesize that above and beyond caring about behavior, highly self-controlled people should react to others' immoral mental states in a more moralizing manner, including ascriptions of moral wrongness and blameworthiness, as well as character judgments. Importantly, such a result would not only advance research at the intersection of self-control and morality, but also offer novel insights on how interindividual differences in self-control shape social perception.

\section{The Present Research}

We propose that the moralization of mental states is shaped by interindividual differences in self-control. This effect should (partly) be driven by ascribing greater control to others over their immoral mental states (control ascriptions), informed by perceived control over one's own mental states (control perceptions). This basic model is depicted in Figure 1. 


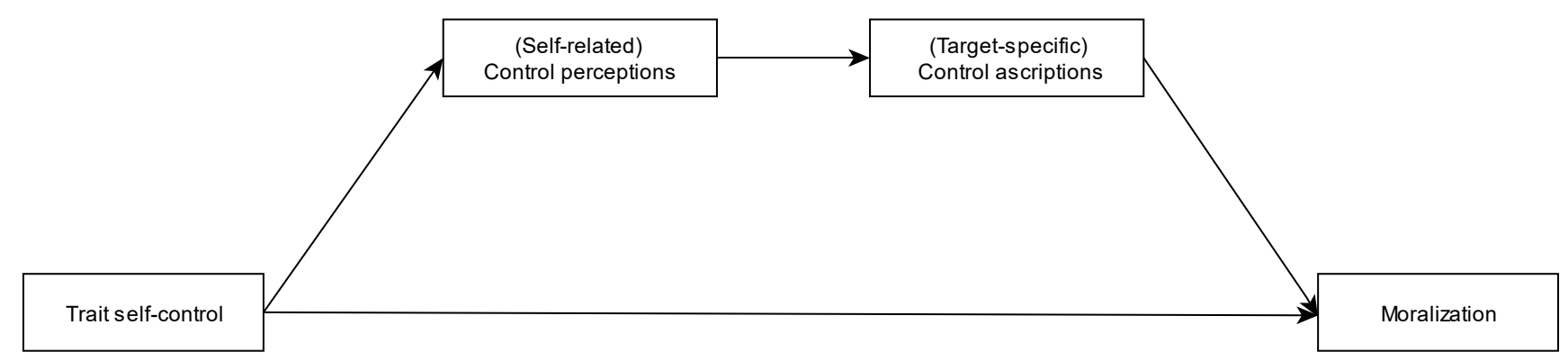

Figure 1. Basic theoretical model tested in in the present work. Self-related control perceptions, target-specific control ascriptions, and moralization all refer to mental states.

We investigated these hypotheses in eight studies, taking into account multiple relevant additional variables. Building on the procedures and materials developed by Cohen and Rozin (2001; Cohen, 2003), Studies 1a and 1b investigated the relationship between perceivers' TSC and the moralization of a target's thoughts about an extramarital affair. Employing structural equation modeling, Study 1a tested control ascriptions as a mediator. It furthermore explored the role of the target's perceived likelihood to act upon his thoughts. In Study 1b, we additionally assessed moral condemnation of the behavior itself to examine whether TSC predicts moralization of mental states via control ascriptions above and beyond higher moral standards for behavior. Studies $1 \mathrm{~b}$ to $2 \mathrm{~b}$ furthermore sought to generalize these findings to scenarios in which the target had no possibility to act upon his thoughts. Studies 3 a to 4 b elucidated why individuals high in TSC ascribe greater control over mental states to others and show stronger moralization, examining the role of perceived abilities to control one's own mental states. Specifically, drawing on existing self-report measures of emotion regulation (Study 3a) and mind-wandering (Study 3b), we tested whether individuals who perceive difficulties (vs. ease) to control their own mental states (i.e., emotions resp. thoughts) judge targets' immoral mental 


\section{SELF-CONTROL AND MORALIZATION OF MENTAL STATES}

states to be less subject to voluntary control across different scenarios. In a mediational model, Study $3 \mathrm{a}$ additionally assessed TSC. Studies $4 \mathrm{a}$ and $4 \mathrm{~b}$ followed a causal-chain approach to mediation. Study 4a manipulated participants' perceived ability to control their own mental states, finding an experimental effect on control ascriptions to others over their immoral mental states. Completing the causal chain, Study 4b manipulated targets' control over their thoughts, providing novel experimental evidence for the hypothesis that control ascriptions promote the moralization of mental states.

For all studies, we report all relevant measures, all conditions, and all data exclusions. Sample sizes were determined based on prior research (e.g., De Castella et al., 2017; Monroe et al., 2017), with the goal of being able to detect small to medium effects between experimental groups with at least $80 \%$ statistical power. For correlational studies, we aimed at collecting sufficient data to obtain stable effect size estimates for the basic effect, that is, the relation between TSC and the criterion variable (i.e., in most studies, moralization). To that end, we generally targeted a final sample size of approximately 250 (Schönbrodt \& Perugini, 2013). Materials for all studies can be found in the appendices and data and supplementary materials (SOM) can be accessed at https://osf.io/2tp5j/?view_only=19f72ff695fc4f66ab394a6c484244ea. The present studies were either approved (in their present or highly similar form) and funded by the Center for Social and Economic Behavior at the University of Cologne, Germany, or approved by the Ethics Review Board of Bielefeld University, Germany.

\section{Study 1a}

Two initial studies were based on the design of Cohen and Rozin's (2001; Cohen, 2003; Cohen \& Rankin, 2004) studies and investigated whether trait differences in self-control are associated with a tendency to moralize others' thoughts. We hypothesized that participants' TSC 


\section{SELF-CONTROL AND MORALIZATION OF MENTAL STATES}

scores would positively predict moralization. In addition, and central to our theoretical model, we theorized that perceptions of the target's voluntary control over his thoughts would mediate this relationship.

We additionally assessed the perceived likelihood that the target would act upon his immoral thoughts, in order to ensure that the proposed relationship does not solely rely on perceptions of immoral thoughts leading to immoral behavior. Previous research indeed found that the moralization of mental states may be associated with the (perceived) likelihood of corresponding behavior (Cohen \& Rozin, 2001). In particular, perceptions of the target being capable of choosing his mental state might entail perceptions of the target desiring it and evaluating it positively. Someone with such a "meta-desire" (Pizarro et al., 2003) might, in turn, be more motivated to exert the corresponding behavior. Therefore, a sequential mediation model tested the effect of TSC on moralization via control ascriptions (regarding mental states) and likelihood perceptions (regarding behavior). The simple indirect effect of TSC on moralization via control ascriptions constituted the primary test of our hypothesis (e.g., Alicke, 2000).

\section{Method}

Participants and design. Given that Study 1a was our initial study and we were agnostic with respect to effect sizes, we recruited 400 U.S. American participants on Amazon's Mechanical Turk (MTurk) for a survey on personality and situation perception. They received $\$ 0.35$ as compensation. Four participants were excluded because they indicated having answered randomly or purposely wrong (two individuals) or indicated they had participated multiple times in the survey (two individuals), resulting in a final $N=396$ (187 female, 209 male, $M_{\mathrm{age}}=35.48$, $\left.S D_{\text {age }}=11.97\right)$. Participants completed a measure of TSC. Further, in a vignette task, they read about a target having an immoral mental state and responded to subsequent items designed to 


\section{SELF-CONTROL AND MORALIZATION OF MENTAL STATES}

assess the moralization of the target's mental state. Order of the measures of TSC and moralization was counterbalanced across participants.

Procedure and materials. Participants completed the Self-Control Scale, the most widely used, 36-item validated measure of TSC (Tangney et al., 2004). Sample items read "People would say that I have iron self-discipline," "I am lazy" (reverse-coded), and "I am able to work effectively toward long-term goals." These items were rated on a five-point scale $(1=$ not at all, $5=$ very much). Responses were collapsed to form an index of TSC. The remaining study materials closely followed those of Studies 2 and 4 from Cohen and Rozin (2001). Specifically, as a measure of moralization of mental states, participants read a vignette about a married man, Mr. B., who consciously entertained thoughts about having an affair with his female colleague (adapted from Cohen \& Rozin, 2001):

Mr. B. is a 2005 graduate of a University. He graduated with a 3.6 GPA with a BA in English and a minor in Communications. Since graduation, Mr. B. has worked at an entry-level job in a marketing firm. Mr. B. married his University sweetheart six months after they both had their graduation from University. Mr. B. and his wife do not have any children.

One of Mr. B.'s colleagues at work is a very attractive woman. This woman sometimes flirts with Mr. B. and they both know that she would be willing to have a sexual affair with him. Sometimes, Mr. B. consciously entertains thoughts about having a sexual affair with his colleague, thinking about where they would have an affair and what it would be like to have an affair with her.

Subsequently, participants responded to three items taken from Cohen and Rozin (2001) that assessed on seven-point scales moral judgments of the target's thoughts and character, for 


\section{SELF-CONTROL AND MORALIZATION OF MENTAL STATES}

example, “My gut reaction is that Mr. B.'s consciously entertaining thoughts about having a sexual affair with his colleague is wrong" $(1=$ strongly disagree, 7 = strongly agree ; for complete materials for all studies, see Appendices A-H). In line with Cohen and Rozin (2001), responses were collapsed to obtain a measure of moralization of mental states, with higher scores indicating stronger moral condemnation.

On the next screen, we assessed potential mediating processes with two items. Specifically, participants were asked how likely they thought that the target was to have a sexual affair with his colleague (likelihood perceptions; 1 = very unlikely, 7 = very likely), and how much voluntary control over his thoughts they ascribed to the target, "How much control do you think Mr. B. has over his consciously entertaining thoughts about having a sexual affair with his colleague? In other words, are his thoughts involuntary, or do they result from voluntary effort?" (control ascriptions; 1 = completely involuntary, 7 = completely voluntary; Cohen \& Rozin, 2001). On the next screen, four items (Cohen \& Rozin, 2001) assessed participants' more general (i.e., target-unrelated) belief that morality is contingent upon (or informed by) mental states (e.g., "Being a moral person is more a matter of what is in your heart rather than what you do;" $1=$ strongly disagree, 7 = strongly agree). As the present research focused on target-specific perceptions rather than such general moralization of mental states, results for this measure are reported in the SOM (p. 4). Finally, participants provided demographic information.

\section{Results and Discussion}

Mean values, standard deviations, and raw correlations for Studies 1a-3b can be found in Tables 1-6. All regression analyses were performed using the lavaan package for R (version 0.67; Rosseel, 2012), using "normal" maximum likelihood estimation (based on the biased sample covariance matrix) to obtain our parameter estimates. Standard errors were computed using a 


\section{SELF-CONTROL AND MORALIZATION OF MENTAL STATES}

bootstrapping procedure with 5,000 resamples; Confidence intervals are based on bias-corrected adjusted bootstrap percentiles (BCa). Missing values were estimated using a full information maximum likelihood procedure (FIML; Yuan \& Bentler, 2000).

Table 1

Descriptive Statistics and Zero-Order Correlations of Main Variables in Study $1 a$

\begin{tabular}{|c|c|c|c|c|c|}
\hline Variables & $M(S E)$ & 1 & 2 & 3 & 4 \\
\hline $\begin{array}{l}\text { 1. Trait self- } \\
\text { control }\end{array}$ & $3.44(0.61)$ & .93 & & & \\
\hline $\begin{array}{l}\text { 2. Control } \\
\text { ascriptions }\end{array}$ & $4.77(1.60)$ & $.198 * * *$ & & & \\
\hline $\begin{array}{l}\text { 3. Likelihood } \\
\text { perceptions }\end{array}$ & $4.49(1.54)$ & .036 & $.354 * * *$ & & \\
\hline 4. Moralization & 4.54 (1.17) & $.208 * * *$ & $.441 * * *$ & $.506 * * *$ & .68 \\
\hline
\end{tabular}

Notes. $* * * p<.001$. The diagonal represents Cronbach's $\alpha$.

We entered TSC, control ascriptions, likelihood perceptions and moralization into a structural equation model testing a serial mediation of the effect of self-control on moralization via control ascriptions and likelihood perceptions (Figure 2).

In line with our hypothesis, participants' TSC overall positively predicted moralization of mental states, as indicated by a significant total effect, $\beta(S E)=.21(.05), p<.001,95 \% \mathrm{CI}_{\beta}[.10$, .31]. On the level of individual paths, we found that TSC significantly predicted control ascriptions, $\beta(S E)=.20(.05), p<.001,95 \% \mathrm{CI}_{\beta}[.09, .30]$, but not perceived likelihood, $\beta(S E)$ $=-.04(.05), p=.447,95 \% \mathrm{CI}_{\beta}[-.13, .06]$. Control ascriptions predicted likelihood perceptions, $\beta$ $(S E)=.36(.05), p<.001,95 \% \mathrm{CI}_{\beta}[.25, .47]$. The latter, in turn, predicted moralization, $\beta(S E)=$ $.41(.05), p<.001,95 \% \mathrm{CI}_{\beta}[.32, .50]$. 
SELF-CONTROL AND MORALIZATION OF MENTAL STATES

Directly testing our hypothesis, the indirect effect via control ascriptions was significant individually, $\beta(S E)=.05(.02), p=.001,95 \% \mathrm{CI}_{\beta}[.03, .09]$. In contrast, likelihood perceptions did not emerge as an individual mediator: The simple indirect effect of TSC on moralization via likelihood perceptions was non-significant, $\beta(S E)=-.01(.02), p=.445,95 \% \mathrm{CI}_{\beta}[-.05, .02]$. In addition, a significant indirect effect of TSC on moralization via control and likelihood perceptions in sequence emerged, $\beta(S E)=.03(.01), p=.001,95 \% \mathrm{CI}_{\beta}[.01, .05]$, suggesting that likelihood perceptions play a role in the relationship between TSC and moralization, yet are not solely responsible for this relationship.

Controlling for the indirect effects, the total effect of participants' TSC on moralization was reduced, but remained significant; direct effect: $\beta(S E)=.14(.04), p=.001,95 \% \mathrm{CI}_{\beta}[.06$, $.22]$.

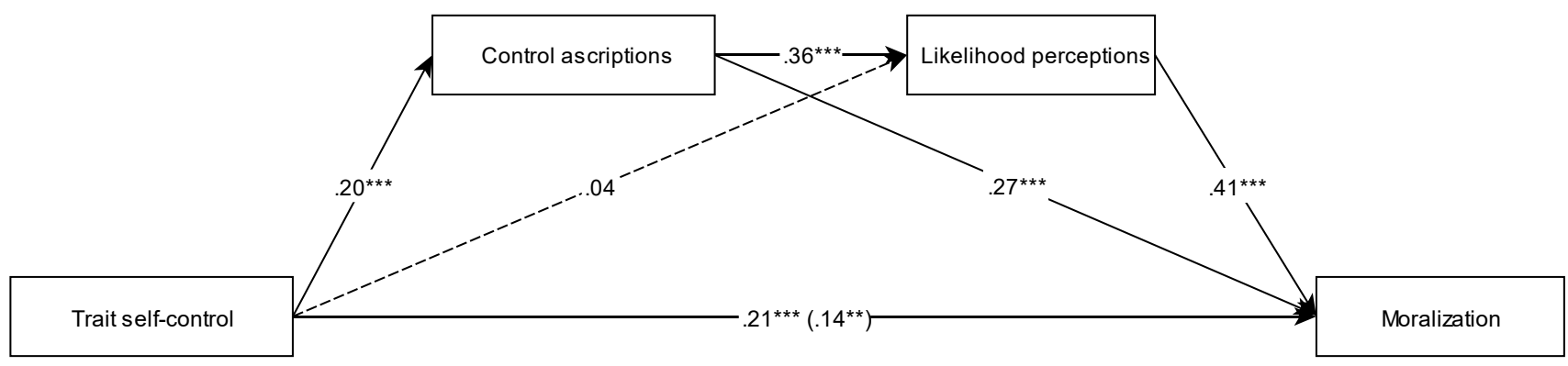

Figure 2. Structural equation model of the effect of trait self-control on moralization via ascriptions of control to the target over his mental states and perceived likelihood of the target to show the behavior. Numbers represent standardized regression coefficients, Study $1 \mathrm{a}, * * p<.01$, $* * * p<.001$.

These results provide initial evidence that individuals with higher dispositional selfcontrol moralize others' immoral mental states more strongly. The effect of TSC on moralization 


\section{SELF-CONTROL AND MORALIZATION OF MENTAL STATES}

appears to partly rely on enhanced ascriptions of control that the target has over his thoughts. Results further suggest that control ascriptions are associated with an enhanced expectation that the target will act correspondingly. While this association contributed to the overall effect, control ascriptions emerged as an individual mediator of the relationship between TSC and moralization, regardless of expectations that the target would act upon his thoughts. Expectations about behavior thus do not appear as a necessary condition for high TSC individuals to moralize mental states. Consequently, and in line with our theoretical argument based on the prominent role of control ascriptions in prior work on moral judgment (e.g., Alicke, 2000; Cohen \& Rozin, 2001; Cusimano \& Goodwin, 2019), we focused on this process in our remaining studies.

\section{Study 1b}

Study 1a provided initial evidence for an association between TSC and the tendency to judge others based on their immoral thoughts, above and beyond the perceived likelihood of acting upon them. However, participants may have suspected that someone who fantasizes about an affair with his colleague might have previously engaged in related behaviors (such as flirting with that colleague), and therefore still base their judgment on assumed behavior rather than the mental content alone. To address this shortcoming, Study $1 \mathrm{~b}$ employed a modified version of this scenario in which the target cannot engage in the behavior, thereby holding behavior likelihood constant (at practically zero). We again hypothesized that TSC would predict moralization of the target's mental states, and that this effect would be mediated by control ascriptions.

We additionally explored another potentially relevant alternative process related to immoral behavior. Specifically, given that people with higher TSC show less deviant behavior themselves (e.g., Tangney et al., 2004), they might also apply stricter moral standards to behavior. Condemning a behavior might affect judgments of targets who think about or desire 
SELF-CONTROL AND MORALIZATION OF MENTAL STATES

this behavior, irrespective of any expectations of the target being able to control their thoughts and/or behavior. To our knowledge, the association between TSC and moral judgments of others' behaviors has not been tested yet. In order to explore this potential additional pathway, Study $1 b$ therefore included a measure of condemnation of the corresponding immoral behavior. We tested a parallel mediation model of the effect of TSC on the moralization of mental states.

\section{Method}

Participants and design. We recruited 311 U.S. American participants on MTurk for a survey on personality and situation perception. They received $\$ 0.35$ as compensation. Three participants were excluded because they indicated that they had participated multiple times in the survey (no one indicated random/wrong responding), resulting in a final $N=308$ (166 female, 142 male, $\left.M_{\text {age }}=34.74, S D_{\text {age }}=11.94\right)$. Participants again completed a measure of TSC preceded by a vignette task to assess moralization of mental states similar to that used in Study 1a.

Procedure and materials. Materials again closely followed previous work (Cohen, 2003; Cohen \& Rankin, 2004; Cohen \& Rozin, 2001). Participants read a vignette in which the target, Mr. B., was described to engage in conscious thoughts about an affair with a celebrityactress Natalie Portman (see Cohen, 2003, Study 3). The nature of the target's “conscious thoughts" was clarified via more concrete descriptions (see Cohen \& Rankin, 2004; Cohen \& Rozin, 2001):

Mr. B. is a 2005 graduate of a University. He graduated with a 3.6 GPA with a BA in English and a minor in Communications. Since graduation, Mr. B. has worked at an entry level job in a marketing firm. Mr. B. married his University sweetheart six months after they both had their graduation from University. Mr. B. and his wife do not have any children. Mr. B. has never cheated on his wife by having an affair with someone else. 
SELF-CONTROL AND MORALIZATION OF MENTAL STATES

For years, Mr. B. has followed the career of the actress Natalie Portman with great interest, and he has always found her to be extremely attractive. Although Mr. B. knows that he will never meet Natalie Portman, he often fantasizes about her. At on average four times a week for on average 10 minutes, Mr. B. consciously entertains thoughts about having a sexual affair with Natalie Portman, thinking about where they would have an affair and what it would be like to have an affair with her.

Subsequently, participants answered five moralization items that assessed moral judgments of the target's mental states and character (Cohen, 2003). Sample items read "My gut reaction is that Mr. B.'s consciously entertaining thoughts about having a sexual affair with Natalie Portman is wrong" and "Mr. B. is a bad person.” All items were rated on seven-point scales $(1=$ strongly disagree, $7=$ strongly agree $; 1=$ very negatively, $7=$ very positively, reverse scored; see Appendix B). Responses were collapsed to form a reliable index of moralization, with higher values indicating more negative judgments of the target's thoughts and character.

This measure was followed by the control ascriptions item from Study 1a. Participants additionally completed a single item assessing general moralization of mental states taken from Study 1a (see Cohen, 2003; Cohen \& Rozin, 2001; see Appendix B; see SOM for results). Moreover, we assessed moral judgments of having an affair in general as a measure of behavior condemnation, "How would it affect your judgment of a person's character to know that they actually did have a sexual affair?" (1 = very negatively, 7 = very positively, reverse coded $)$. Subsequently, participants completed the validated 13-item short version of the Self-Control Scale (Brief Self-Control Scale; Tangney et al., 2004) and demographic questions.

\section{Results and Discussion}




\section{SELF-CONTROL AND MORALIZATION OF MENTAL STATES}

Table 2

Descriptive Statistics and Zero-Order Correlations of Main Variables in

Study $1 b$

\begin{tabular}{|c|c|c|c|c|c|}
\hline Variables & $M(S E)$ & 1 & 2 & 3 & 4 \\
\hline $\begin{array}{l}\text { 1. Trait self- } \\
\text { control }\end{array}$ & $3.40(0.76)$ & .89 & & & \\
\hline $\begin{array}{l}\text { 2. Control } \\
\text { ascriptions }\end{array}$ & $4.97(1.52)$ & $.261 * * *$ & & & \\
\hline $\begin{array}{l}\text { 3. Behavior } \\
\text { condemnation }\end{array}$ & $5.71(1.26)$ & $.156^{* * *}$ & .101 & & \\
\hline 4. Moralization & $3.46(1.31)$ & $.169 * *$ & $.280 * * *$ & $.278 * * *$ & .87 \\
\hline
\end{tabular}

We entered TSC scores, control ascriptions, behavior condemnation, and moralization of mental states into a structural equation model. Control ascriptions and behavior condemnation were included as parallel (and therefore independent) mediators (Figure 3). TSC again positively predicted how strongly participants moralized the target's thoughts, as indicated by a significant total effect, $\beta(S E)=.17(.06), p=.005,95 \% \mathrm{CI}_{\beta}[.05, .29]$. Further, TSC predicted both control ascriptions, $\beta(S E)=.26(.06), p<.001,95 \% \mathrm{CI}_{\beta}[.15, .37]$, and behavior condemnation, $\beta(S E)=$ $.16(.06), p=.008,95 \% \mathrm{CI}_{\beta}[.04, .27]$. Both control ascriptions, $\beta(S E)=.24(.06), p<.001,95 \%$ $\mathrm{CI}_{\beta}[.13, .35]$, and behavior condemnation, $\beta(S E)=.24(.05), p<.001,95 \% \mathrm{CI}_{\beta}[.15, .35]$, significantly predicted moralization of the target's mental states. Central to the present research, and replicating our main finding from the first study, a significant indirect effect via control ascriptions emerged, $\beta(S E)=.06(.02), p=.003,95 \% \mathrm{CI}_{\beta}[.03, .11]$. Likewise, the indirect effect of TSC on moralization via behavior condemnation was significant, $\beta(S E)=.04(.02), p=.014$, $95 \% \mathrm{CI}_{\beta}[.01, .08]$. Controlling for these indirect effects reduced the total effect to a nonsignificant direct effect, $\beta(S E)=.07(.06), p=.245,95 \% \mathrm{CI}_{\beta}[-.05, .19]$. 


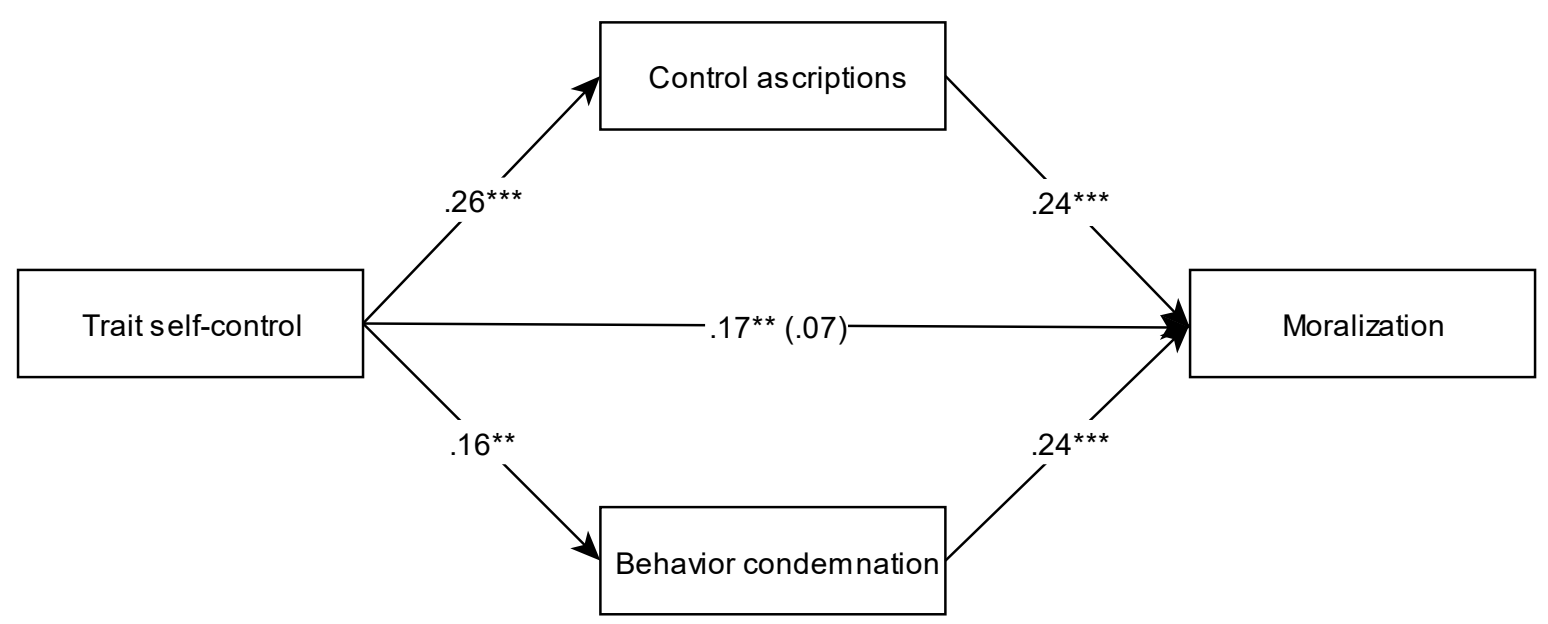

Figure 3. Structural equation model of the effect of trait self-control on moralization via ascriptions of control to the target over his mental states and condemnation of the immoral behavior. Numbers represent standardized regression coefficients, Study $1 \mathrm{~b}, * * p<.01$, ***p $<$ .001 .

In Study 1b, participants with higher TSC again moralized a target's mental states more strongly. This was the case even though that person could clearly not put his thoughts into action. Analyses further revealed that ascribed control over mental states and condemnation of the behavior — which both emerged as parallel mediators - fully accounted for the relationship between TSC and moralization of mental states. These results lend further support to the central role of ascriptions of control in explaining the effect of TSC on moralization of mental statesabove and beyond people's moral standards for the corresponding behavior. The present results thus conceptually replicate the core findings from Study 1a, while simulanteously consideringand providing novel evidence of - the effect of TSC on behavior condemnation. Building on prior methodology (e.g., Cohen \& Rozin, 2001), Studies 1a and 1b investigated thoughts related to having an extramarital affair. To increase the generalizability of our findings, for the following 


\section{SELF-CONTROL AND MORALIZATION OF MENTAL STATES}

studies, we designed novel materials with the purpose of rendering it even less likely that participants would imagine the target engaging in the imagined or any related behavior.

\section{Study 2a}

Arguably, an extramarital affair may mean breaking mutual agreements or general moral rules and afflicting harm on one's spouse as a side-effect of one's behavior. However, people may often desire harm for another person more directly, and enjoy thinking about how harm might befall that person (Kenrick, 2011). Importantly, one set of studies found that people morally condemn those who experience malevolent desires and pleasure at others' misfortunes (Gromet et al., 2016). Study 2a was therefore designed to replicate the findings from Studies 1a and $1 \mathrm{~b}$ in a setting where a target experiences dislike for a colleague and enjoys thinking about sabotaging that colleague's work. Additionally, Study 2a sought to replicate Study 1b, again assessing moral condemnation of actually engaging in the corresponding behavior. We again expected control ascriptions to mediate the effect of TSC on moralization, and behavior condemnation to function as a parallel mediator.

\section{Method}

Participants and design. We recruited 332 U.S. American participants on MTurk for a survey on personality and situation perception. They received $\$ 0.40$ as compensation. Three participants were excluded because they indicated having participated in the survey more than once. Five further participants were excluded because they admitted to having answered randomly or purposely wrong, resulting in a final $N=324$ (144 female, 178 male, 2 other, $M_{\text {age }}=$ $\left.36.45, S D_{\text {age }}=11.09\right)$. The study design closely followed that of Study $1 \mathrm{~b}$, with participants completing a measure of TSC and a new vignette task designed to assess the moralization of mental states. Order of these measures was counterbalanced between participants. 


\section{SELF-CONTROL AND MORALIZATION OF MENTAL STATES}

Procedure and materials. Participants again completed the Brief Self-Control Scale (Tangney et al., 2004). Further, they read a short vignette about two colleagues who were described as biological scientists. The target person, Christopher, disliked his colleague, Alan, and enjoyed thinking about sabotaging Alan's work. Importantly, it was made explicit that he did not have an opportunity to act upon his desires, thereby rendering any behavioral implications that the previous vignettes might have had rather unlikely. Instead, the current vignette focused on the target's malevolent desire and pleasure at his thoughts:

Christopher and Alan are biology scientists at a university. They investigate in the same domain, a stem of nonhazardous tropical bacteria, and are at about the same career level. Christopher does not like Alan, and resents him his recent successes.

Even though Christopher does not have access to the laboratory where Alan works, because the two belong to different departments, Christopher sometimes fantasizes about destroying all of the special experimental cultures in Alan's lab. He takes pleasure in thinking how Alan would have to create all cell cultures anew in cumbersome evening hours.

Subsequently, participants completed a six-item measure of moralization of mental states, for example "It is morally wrong for Christopher to fantasize about destroying Alan's experimental cultures" and "Christopher has bad character" (see Appendix C). In line with previous research (Cohen \& Rozin, 2001), participants' answers to these items were collapsed to form a moralization score. Subsequently, two items based on prior work (Cohen \& Rozin, 2001) and Studies 1a and 1b assessed ascriptions of control: “Christopher's entertaining thoughts about destroying Alan's experimental cultures is completely involuntary" (reverse coded) and 


\section{SELF-CONTROL AND MORALIZATION OF MENTAL STATES}

“Christopher's fantasies about destroying Alan's experimental cultures result from voluntary effort." All items were judged on a seven-point scale $(1=$ strongly disagree, $7=$ strongly agree $)$.

In addition, we assessed behavior condemnation with three items similar to those in Study 1b, for example "What would you think if Christopher did something else to harm Alan's work?" (1 = extremely immoral/very negatively, 7 = extremely moral/very positively; reverse coded). Responses were collapsed to create an index of behavior condemnation. At the end of the study, participants provided demographic information.

\section{Results and Discussion}

Table 3

Descriptive Statistics and Zero-Order Correlations of Main Variables in Study $2 a$

\begin{tabular}{|c|c|c|c|c|c|}
\hline Variables & $M(S E)$ & 1 & 2 & 3 & 4 \\
\hline $\begin{array}{l}\text { 1. Trait self- } \\
\text { control }\end{array}$ & $3.43(0.78)$ & .91 & & & \\
\hline $\begin{array}{l}\text { 2. Control } \\
\text { ascriptions }\end{array}$ & $4.84(1.43)$ & $.239 * * *$ & .83 & & \\
\hline $\begin{array}{l}\text { 3. Behavior } \\
\text { condemnation }\end{array}$ & $6.34(1.10)$ & $.101^{\dagger}$ & $.147 * *$ & .87 & \\
\hline 4. Moralization & $4.42(1.46)$ & $.145^{* *}$ & $.381 * * *$ & .060 & .91 \\
\hline
\end{tabular}

All variables were entered into the same parallel mediation model as in Study $1 \mathrm{~b}$. Participants' TSC scores again positively predicted moralization, as indicated by a significant total effect, $\beta(S E)=.14(.07), p=.028,95 \% \mathrm{CI}_{\beta}[.01, .27]$. TSC also predicted both control ascriptions, $\beta(S E)=.24(.06), p<.001,95 \% \mathrm{CI}_{\beta}[.13, .35]$, and behavior condemnation, $\beta(S E)=$ $.10(.04), p=.019,95 \% \mathrm{CI}_{\beta}[.02, .19]$. Control ascriptions, in turn, predicted moralization, $\beta(S E)$ $=.37(.06), p<.001,95 \% \mathrm{CI}_{\beta}[.25, .48]$. In contrast, behavior condemnation did not predict 


\section{SELF-CONTROL AND MORALIZATION OF MENTAL STATES}

moralization in this study, $\beta(S E)=.00(.04), p=.992,95 \% \mathrm{CI}_{\beta}[-.09, .09]$. Importantly, and as predicted, the indirect effect of self-control on moralization via control ascriptions was significant, $\beta(S E)=.09(.02), p<.001,95 \% \mathrm{CI}_{\beta}[.05, .14]$. The predicted indirect effect of TSC on moralization of mental states via behavior condemnation, however, was non-significant, $\beta$ $(S E)=.00(.00), p=.993,95 \% \mathrm{CI}_{\beta}[-.01, .01]$. Controlling for these indirect effects reduced the total effect to a non-significant direct effect, $\beta(S E)=.06(.06), p=.358,95 \% \mathrm{CI}_{\beta}[-.06, .18]$.

Study $2 \mathrm{a}$ extends the central findings from Studies $1 \mathrm{a}$ and $1 \mathrm{~b}$ to a behavior more representative of the domain of harm. Participants with higher TSC judged a target to have greater control over his malevolent thoughts, which mediated the effect of TSC on moralization of his mental states. These effects again emerged independently of behavior condemnation, and despite the fact that the target could not act upon his thoughts. Behavior condemnation was again predicted by TSC. However, condemning a behavior that the target would certainly not exert did not predict moralization of mental states, and hence not emerge as another mediator.

An additional study with an otherwise identical design (Study 2c, see SOM, p. 9) assessed control ascriptions with a slightly modified three-item measure. In that study, the predicted indirect effect via control ascriptions was not significant. Nevertheless, taken together, the studies conducted so far indicated that high TSC individuals moralize mental states more strongly - even when targets' thoughts are purely hypothetical and cannot be be executed. What is more, this relationship seems to be partly driven by greater voluntary control over mental states ascribed to targets. In order to once again replicate this central finding, and for the sake of construct validity, Study $2 \mathrm{~b}$ was designed to assess control ascriptions with an extended measure derived from the literature on free will beliefs.

\section{Study 2b}




\section{SELF-CONTROL AND MORALIZATION OF MENTAL STATES}

Lay intuitions about free will comprise a "chosen, desired intentional action absent constraints" (Monroe et al., 2014, p. 108; see also Feldman et al., 2014; Monroe et al., 2017; Monroe \& Malle, 2010, 2017; Nahmias \& Thompson, 2014). In Study 2b, we adapted this conceptualization of free will to the mental realm and developed a novel measure of control ascriptions to extend the findings of Studies 1a-2a. Specifically, this novel scale comprised two items each assessing the target's perceived capacity of choice, absence of constraints, and alignment with the target's desires or intentionality, all with reference to mental states. We predicted that control ascriptions would again mediate the effect of TSC on moralization.

\section{Method}

Participants and design. We recruited 315 U.S. American participants on MTurk for a survey on personality and situation perception. They received $\$ 0.30$ as compensation. In total, 15 additional participants were excluded because they indicated having answered randomly or purposely wrong (4 individuals), or indicated they had participated multiple times in the survey (7 individuals), or because they failed an attention check (6 individuals; multiple applicable criteria possible), resulting in a final $N=300$ (144 female, 153 male, 3 other/n.a., $M_{\text {age }}=35.64$, $\left.S D_{\text {age }}=11.44\right)$. Again, participants completed a measure of TSC and a vignette task to assess the moralization of mental states. These measures were presented in counterbalanced order.

Procedure and materials. Participants again completed the Brief Self-Control Scale (Tangney et al., 2004). They also read the same vignette as in Study 2a about a biological scientist fantasizing about sabotaging his colleague. They then completed our novel measure of control ascriptions comprising six items in a fixed random order on seven-point scales $(1=$ strongly disagree, 7 = strongly agree). Sample items read "Christopher freely chooses to fantasize about destroying Alan's experimental cultures," (capacity of choice) "Christopher 


\section{SELF-CONTROL AND MORALIZATION OF MENTAL STATES}

could prevent his fantasies about destroying Alan's experimental cultures, if he wanted," (absence of constraints) and “Christopher's thoughts about destroying Alan's experimental cultures are intentional" (intentionality; see Appendix D). Responses were collapsed to form an index of control ascriptions. ${ }^{1}$ On the next screen, participants completed the six moralization items from Study 2a. Subsequently, participants were instructed to select a certain number on a seven-point scale, serving as an attention check, and provided demographic information.

\section{Results and Discussion}

Table 4

Descriptive Statistics and Zero-Order Correlations of Main

Variables in Study $2 b$

\begin{tabular}{|c|c|c|c|c|}
\hline Variables & $M(S E)$ & 1 & 2 & 3 \\
\hline $\begin{array}{l}\text { 1. Trait self- } \\
\text { control }\end{array}$ & $3.33(0.75)$ & .88 & & \\
\hline $\begin{array}{l}\text { 2. Control } \\
\text { ascriptions }\end{array}$ & $5.75(1.06)$ & $.243 * * *$ & .82 & \\
\hline 3. Moralization & $4.36(1.43)$ & $.280 * * *$ & $.296 * * *$ & .89 \\
\hline
\end{tabular}

In order to determine whether control ascriptions mediated the effect of TSC on moralization, we ran a mediation analysis (Figure 4). Participants' TSC scores again significantly predicted moralization, as indicated by a significant total effect, $\beta(S E)=.28(.06), p<.001,95 \%$ $\mathrm{CI}_{\beta}[.16, .39]$. In addition, TSC predicted control ascriptions, $\beta(S E)=.24(.06), p<.001,95 \%$ $\mathrm{CI}_{\beta}[.13, .36]$. Control ascriptions, in turn, predicted moralization, $\beta(S E)=.24(.05), p<.001$, $95 \% \mathrm{CI}_{\beta}[.14, .35]$. Consistent with predictions, a significant indirect effect emerged, $\beta(S E)=$

\footnotetext{
${ }^{1}$ Unexpectedly, a single reversed coded item correlated negatively with the overall control ascriptions scale $(r=-$ .32 , corrected item-total correlation), with reliability being considerably higher when excluding this item $(\alpha=.82$ versus $\alpha=.64)$. Therefore, we created an average score of the five remaining items. Results for the six-item scale are, however, highly similar.
} 


\section{SELF-CONTROL AND MORALIZATION OF MENTAL STATES}

$.06(.02), p=.002,95 \% \mathrm{CI}_{\beta}[.03, .11]$. As a result, the direct effect, while remaining significant, was reduced, $\beta(S E)=.22(.06), p<.001,95 \% \mathrm{CI}_{\beta}[.10, .33]$, indicating mediation.

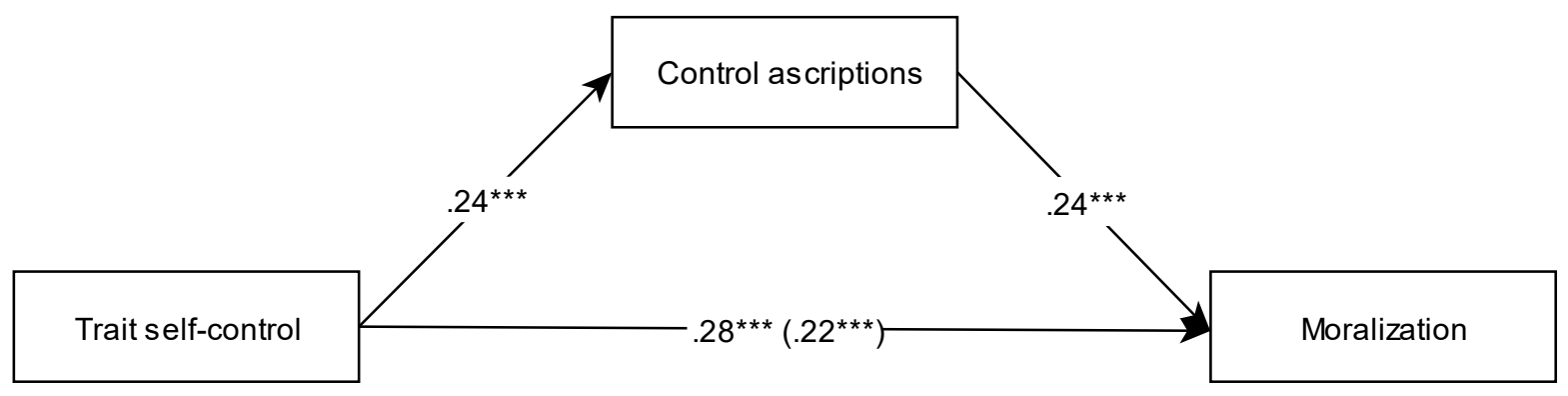

Figure 4. Effect of trait self-control on moralization via ascriptions of control to the target over his mental states. Numbers represent standardized regression coefficients, Study $2 b$, $* * * p<.001$.

Using a novel, multiple-item measure of control ascriptions derived from the literature on free will beliefs, these results corroborate our previous findings, including a direct replication of the relationship between TSC and moralization we found in Study 2a. Taken together, Studies 1a-2b provide evidence for our hypothesis that high TSC people moralize others' mental states more strongly. Furthermore, consistent indirect effects suggest that this amplified moralization at least partly stems from elevated ascriptions of control to targets over their immoral mental states. We designed the next study to provide a more fine-grained examination of the proposed process while additionally investigating a different population.

\section{Study 3a}

The hypotheses tested in Studies 1a-2b relied on the assumption that highly selfcontrolled individuals perceive themselves as capable of controlling their undesired mental states, and that egocentric projection leads them to assume that others are able to do so as well. 


\section{SELF-CONTROL AND MORALIZATION OF MENTAL STATES}

However, thus far, we have not empirically addressed this rationale. In addition, Studies 1a-2b soley relied on U.S. American online samples. The aim of Study 3a was thus threefold: Most importantly, a mediational design sought to deliver support for the role of perceived abilities to control one's own mental states in control ascriptions to others. Furthermore, Study 3a investigated the postulated relationships in a non-online sample from a different population. Finally, we employed a set of newly developed scenarios to assess ascriptions of control to targets experiencing immoral mental states. We hypothesized that TSC would once again predict control ascriptions. This relationship should furthermore be mediated by perceptions of one's own emotion-regulation ability as a proxy for self-perceptions of ability for mental state control. The design and analyses of Study 3a were preregistered

\section{(https://aspredicted.org/blind.php?x=hi88dg).}

\section{Method}

Participants and design. We recruited 250 German students for a study on situation perception in the hallway of a large German university. Participants received a chocolate bar as compensation. 30 participants were excluded for not (correctly) answering an attention check, resulting in a final $N=220$ (139 females, 78 males, 2 diverse, 1 missing, $M_{\text {age }}=23.27, S D_{\text {age }}=$ 4.58).

Procedure and materials. Participants first completed the validated German version of the Brief Self-Control Scale $(1=$ does not apply at all, $5=$ completely applies; Bertrams \& Dickhäuser, 2009). Subsequently, they answered a validated German version of the Emotion Regulation Questionnaire (ERQ; Abler \& Kessler, 2009; Gross \& John, 2003). This questionnaire comprises two subscales: cognitive reappraisal and expressive suppression. The cognitive reappraisal subscale was of primary interest for the present research. It assesses the 


\section{SELF-CONTROL AND MORALIZATION OF MENTAL STATES}

self-reported dispositional tendency towards emotion regulation via cognitive reappraisal, that is, changing one's construal of an emotion-eliciting event. Individuals with higher scores possess "a well-developed capacity for negative mood repair, and show a sense of their capacity for negative mood regulation" (Gross \& John, 2003, p. 355). Reappraisal was measured with six items, for example, "When I want to feel more positive emotion, I change the way I'm thinking about the situation," and "When I'm faced with a stressful situation, I make myself think about it in a way that helps me stay calm." A prior study found a positive association between TSC, the reappraisal subscale of the ERQ, and neurological indicators of emotion-regulation success (Paschke et al., 2016). Responses were collapsed to form an index of cognitive reappraisal.

Four additional items assessed the tendency for expressive suppression (e.g., "When I am feeling negative emotions, I make sure not to express them"). Higher scores are associated with less effective emotion regulation and lower well-being (Gross \& John, 2003). As Study 3a was designed to investigate the role of perceived ability to control one's mental states, rather than controlling one's behaviors related to affective states (e.g., emotion expression), we retained this subscale as a pre-registered control dimension for additional analyses. Participants answered all items on a seven-point scale $(1=$ not true at all, $7=$ completely true $)$. Embedded in the scale was an attention check item prompting participants to select a certain answer option.

On the following page, participants were presented with six newly developed short scenarios (see Appendix E). Each described a target person who experienced an immoral mental state, followed by a single-item measure of control ascriptions. Notably, targets' mental states were unrelated to any behavioral intentions. For example, the "Breakup Scenario" read:

Christina learns that a fellow student was left by her boyfriend and that she is very sad now. Christina, who does not like this fellow student, is happy about that. 
SELF-CONTROL AND MORALIZATION OF MENTAL STATES

The respective control ascriptions item read "Christina could change her being happy about her fellow student having been left by her boyfriend, if she wanted to," which was answered on a seven-point scale $(1=$ not at all, $7=$ completely $)$. Responses to all six items were collapsed to form an index of control ascriptions. At the end of the questionnaire, participants provided demographic information.

\section{Results and Discussion}

Table 5

Descriptive Statistics and Zero-Order Correlations of Main Variables in Study $3 a$

\begin{tabular}{llllll}
\hline Variables & $M(S E)$ & 1 & 2 & 3 & 4 \\
\hline $\begin{array}{l}\text { 1. Trait self- } \\
\text { control }\end{array}$ & $3.07(0.56)$ & .76 & & \\
$\begin{array}{l}\text { 2. Cognitive } \\
\text { reappraisal }\end{array}$ & $4.34(1.09)$ & $.203 * *$ & .80 & \\
$\begin{array}{l}\text { 3. Expressive } \\
\text { suppression }\end{array}$ & $3.48(1.22)$ & -.015 & -.025 & .74 & \\
$\begin{array}{l}\text { 4. Control } \\
\text { ascriptions }\end{array}$ & $5.57(1.13)$ & $.204 * *$ & $.270 * * *$ & -.084 & .84 \\
\hline
\end{tabular}
Notes. $* * p<.01, * * * p<.001$. The diagonal represents Cronbach's $\alpha$.

We ran a mediation analysis in order to determine whether (a) trait-self control predicts control ascriptions regarding others' immoral mental states and (b) whether this effect is mediated by cognitive reappraisal (Figure 5). Participants' TSC scores again predicted control ascriptions, as indicated by a significant total effect, $\beta(S E)=.20(.07), p=.003,95 \% \mathrm{CI}_{\beta}[.07$, $.35]$. In addition, TSC predicted cognitive reappraisal, $\beta(S E)=.20(.07), p=.002,95 \% \mathrm{CI}_{\beta}[.08$, .33]. Cognitive reappraisal, in turn, predicted control ascriptions, $\beta(S E)=.24(.07), p<.001$, $95 \% \mathrm{CI}_{\beta}[.11, .38]$. Consistent with predictions, a significant indirect effect emerged, $\beta(S E)=$ .05 (.02), $p=.035,95 \% \mathrm{CI}_{\beta}[.01, .10]$, indicating mediation. The direct effect remained 


\section{SELF-CONTROL AND MORALIZATION OF MENTAL STATES}

significant, $\beta(S E)=.16(.07), p=.023,95 \% \mathrm{CI}_{\beta}[.03, .30]$. Results remained stable and highly similar when expressive suppression was entered in the model as a covariate, which did not predict control ascriptions in this model, $\beta(S E)=-.08(.06), p=.201,95 \% \mathrm{CI}_{\beta}[-.19, .04]$.

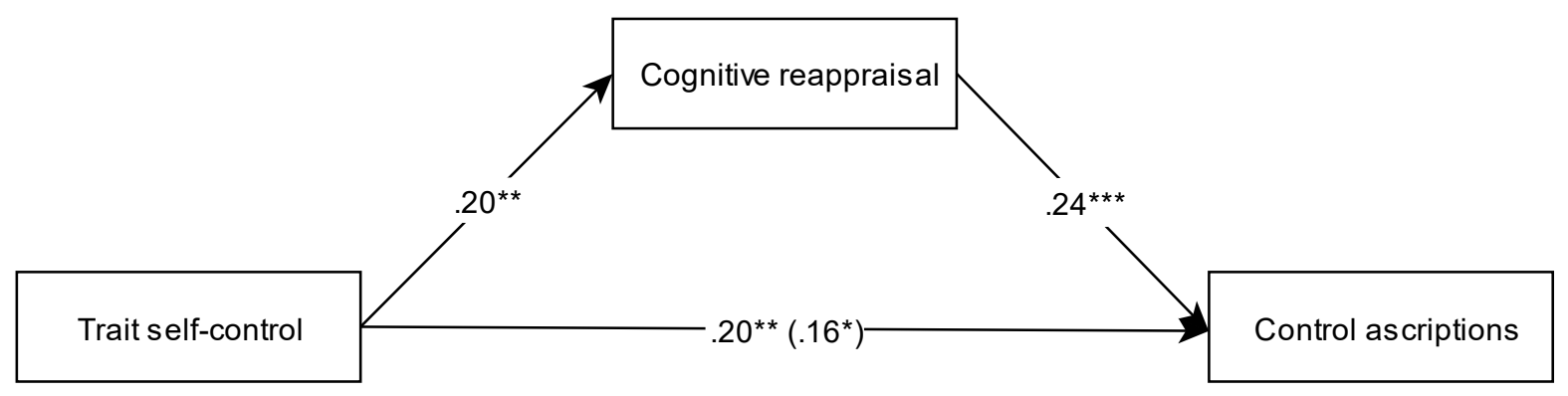

Figure 5. Effect of trait self-control on ascriptions of control to targets over their mental states via cognitive reappraisal. Numbers represent standardized regression coefficients, Study $3 \mathrm{a}, * p<.05, * * p<.01, * * * p<.001$.

These results provide a conceptual replication of path (a) in Studies 1a-2b: In a nononline sample from a different population and with various novel, daily-life scenarios, TSC again predicted the degree of control ascribed to social targets entertaining immoral mental states. These results further elucidate how individuals high in TSC may come to perceive others' mental states in this way: Cognitive reappraisal as an emotion regulation strategy emerged as a mediator. In other words, variations in the degree that highly self-controlled individuals thought they themselves were able to control their own emotional states contributed to their interpretation of others' immoral mental states as subject to voluntary control. In contrast, self-reported expressive suppression was unrelated to control ascriptions. These results are in line with the notion that TSC is associated with control not simply over behavioral impulses, but also internal 


\section{SELF-CONTROL AND MORALIZATION OF MENTAL STATES}

states, specifically emotions (Tangney et al., 2004). Importantly, it thereby seems to shape social perceptions.

In Study 3b, we sought further support for this latter link between self-related control perceptions and target-related control ascriptions with a different operationalization and in yet another population. Instead of relying on MTurk participants or university students, in Study $3 \mathrm{~b}$ we recruited a sample of criminal convicts with a history of substance abuse.

\section{Study 3b}

Aggression, antisocial behavior, and problems with regulating food and alcohol intake have all been conceptualized as important domains of self-control and failure thereof (e.g., Gottfredson \& Hirschi, 1990; Tangney et al., 2004). Consistently, people with a history of criminal behavior, incarceration or alcohol or drug abuse score lower on measures of selfcontrol, including the scale used in the present research (e.g., Allen et al., 1998; Malouf et al., 2014; Tangney et al., 2004; Verdejo-Garcia et al., 2007). In addition, prior work has found a history of frequent drinking or addiction to another substance to be associated with lower belief in free will about one's own and other people's actions (Vonasch et al., 2017). We therefore sought to complement our previous studies with a population of criminal convicts diagnosed with substance abuse - a population arguably characterized by relatively low TSC and adjustment, with potential consequences for self-perceptions of mental state control. Specifically, Study $3 \mathrm{~b}$ attempted a conceptual replication of the association between perceived ability to control one's own mental states and ascriptions of control to others over their immoral mental states.

While Study 3a investigated perceived control over one's emotions, Study $3 b$ focused on control over one's thoughts. To that end, we employed a self-report measure of mind-wandering, 


\section{SELF-CONTROL AND MORALIZATION OF MENTAL STATES}

that is, "engaging in cognitions unrelated to the current demands of the external environment" (Schooler et al., 2011). Prior work differentiates spontaneous, non-deliberate mind-wandering from deliberate, controlled mind-wandering (Carriere et al., 2013). We were particularly interested in uncontrolled, spontaneous shifts of attention, experienced as a stimulus "capturing" one's attention, as a proxy for perceived (low) control over one's mental states that should be associated with reduced ascriptions of control to others (Carriere et al., 2013; Giambra, 1995).

\section{Method}

Participants and design. We hoped to collect data from aproximately 100 participants, allowing to detect an effect as large as the corresponding effect in Study 3a. We were able to collect data from a total of 84 male criminal convicts living in a large secure unit in Germany who voluntarily participated in a study on their personal perceptions, feelings, and attitudes. Eight participants had to be excluded from analyses due to incomplete data (i.e., no responses on the mind-wandering measure $)$, resulting in a final $N=76\left(M_{\text {age }}=30.46, S D_{\text {age }}=6.64\right)$. All participants had been convicted to imprisonment for a range of $15-150$ months $(M d n=49.00)$ for a crime committed in relation to a substance disorder (e.g., drug trafficking; robbery; theft; physical injury) and were currently receiving psychotherapeutical treatment. A considerable proportion had comorbid diagnoses (e.g., personality disorders; gambling disorder). Participants received a chocolate bar as compensation. In a correlational design, participants completed a measure of self-reported mind-wandering followed by the measure of control ascriptions from Study 3a.

Procedure and materials. Closely following earlier work, participants completed a 13item measure of mind-wandering in German language comprised of two different mind- 


\section{SELF-CONTROL AND MORALIZATION OF MENTAL STATES}

wandering scales (Schubert et al., 2020; see Appendix F). ${ }^{2}$ Nine items in total assessed spontaneous mind-wandering as our measure of self-related control perceptions.

Participants first completed the five items of the Mind-Wandering Questionnaire (e.g., "I find myself listening with one ear, thinking about something else at the same time;" Mrazek et al., 2013). Subsequently, they answered an eight-item questionnaire specifically designed to differentiate spontaneous, non-deliberate mind-wandering (subscale MW-Spontaneous, four items, e.g., "It feels like I don't have control over when my mind wanders") from intentional, deliberate mindwandering (subscale MW-Deliberate, four items; "I allow my thoughts to wander on purpose;" Carriere et al., 2013). All items were answered on a seven-point scale $(1=$ almost never/do not agree, 7 = almost always/completely agree . Responses to the Mind-Wandering Questionnaire and the MW-Spontaneous were collapsed to form an index of spontaneous mindwandering (see Schubert et al., 2020). The four remaining items formed an index of deliberate mind-wandering, which we retained as a control scale, paralleling the design of Study 3a. On the following page, participants read the six scenarios from Study 3a in identical fixed random order and rated targets' control over their immoral mental states $(1=$ not at all, $7=$ completely $)$, resulting in an index of control ascriptions.

\section{Results and Discussion}

\footnotetext{
2 The survey was conducted as part of an honor thesis and included additional measures unrelated to the present research. Further details and the complete list of measures are available from the corresponding author upon request.
} 


\section{SELF-CONTROL AND MORALIZATION OF MENTAL STATES}

Table 6

Descriptive Statistics and Zero-Order Correlations of Main

Variables in Study $3 b$

\begin{tabular}{|c|c|c|c|c|}
\hline Variables & $M(S E)$ & 1 & 2 & 3 \\
\hline $\begin{array}{l}\text { 1. Spontaneous } \\
\text { mind-wandering }\end{array}$ & $3.46(1.08)$ & .86 & & \\
\hline $\begin{array}{l}\text { 2. Deliberate } \\
\text { mind-wandering }\end{array}$ & $3.61(1.12)$ & $.516 * * *$ & .68 & \\
\hline $\begin{array}{l}\text { 3. Control } \\
\text { ascriptions }\end{array}$ & $5.18(1.19)$ & $-.285^{*}$ & -.169 & .82 \\
\hline
\end{tabular}

We first regressed control ascriptions on the spontaneous mind-wandering score in a linear regression. As predicted, spontaneous mind-wandering negatively predicted how much control participants ascribed to targets, $\beta(S E)=-.28(.11), p=.009,95 \% \mathrm{CI}_{\beta}[-.49,-.06]{ }^{3} \mathrm{We}$ additionally entered the deliberate mind-wandering score as a predictor in a simultaneous linear regression. The predictive effect of spontaneous mind-wandering on control ascriptions remained significant, $\beta(S E)=-.27(.12), p=.031,95 \% \mathrm{CI}_{\beta}[-.52,-.02]$, whereas deliberate mindwandering did not emerge as a significant predictor, $\beta(S E)=-.03(.11), p=.787,95 \% \mathrm{CI}_{\beta}[-.23$, .21]. These results suggest that to the degree that participants experienced little control over their own thoughts, they ascribed lower control to others over their immoral fantasies and feelings. In contrast, the tendency to deliberately let one's mind wander did not predict control ascriptions.

Taken together, investigating two additional populations beyond MTurk with presumably different degrees of adjustment and TSC, Studies 3a and $3 b$ further elucidate the relationship between TSC and ascribing voluntary control to others over their mental states: Participants ascribed targets greater control to the degree that they perceived themselves as in control over

\footnotetext{
${ }^{3}$ Analyses with the subscale MW-Spontaneous only yielded highly similar results.
} 


\section{SELF-CONTROL AND MORALIZATION OF MENTAL STATES}

their own emotional states and thoughts. These self-related control perceptions appear to underlie the relationship between TSC and control ascriptions to others (Study 3a). Both studies thus also provide novel evidence of how perceptions of one's own self-control abilities (i.e., emotion and thought control) may shape social perceptions more broadly.

\section{Study 4a}

The final set of studies was designed to complement the correlational evidence obtained for our model in Studies 1a-3b by adopting a causal-chain approach to mediation. Specifically, Studies $4 \mathrm{a}$ and $4 \mathrm{~b}$ examined the causal impact of self-related control perceptions on control ascriptions with respect to others' mental states and the resulting effect on moralization. Paralleling our correlational Studies 3a and 3b, Study 4a manipulated participants' perceived control over their own mental states with a manipulation adapted from prior research while assessing control ascriptions to others. Extending prior research (Cusimano \& Goodwin, 2019), Study $4 \mathrm{~b}$ sought novel experimental support for the hypothesized causal effect of ascribing another person control over their mental states on moralization thereof. For these causal-chain studies, we again developed novel scenarios to measure respectively manipulate targets' control over a diverse set of immoral mental states. Study 4a manipulated participants' perceived emotion regulation ability. We hypothesized that reminding participants of their own difficulties (vs. ease) in regulating their emotions would attenuate the tendency to ascribe control to others over their mental states.

\section{Method}

Participants and design. We recruited 220 U.S. American participants on MTurk for a survey on autobiographical experiences and situation perception. They received $\$ 0.50$ as compensation. Ten participants were excluded for failing an attention check ( 5 individuals), for 


\section{SELF-CONTROL AND MORALIZATION OF MENTAL STATES}

indicating to have answered randomly or purposely wrong ( 2 individuals), for self-reported multiple participation in the survey ( 1 individual), or because they did not provide any meaningful examples to the essay task ( 2 individuals), resulting in a final $N=210$ (122 females, 87 males, 1 other/n. a., $\left.M_{\text {age }}=36.81, S D_{\text {age }}=12.38\right)$. Participants were randomly assigned to one of two experimental conditions (high control vs. low control).

Procedure and materials. As a manipulation of perceived control over one's own emotions, participants completed an episodic recall task adapted from previous research (De Castella et al., 2018). Specifically, in the low-control (high-control) condition, participants were instructed to "recall two situations from your own life when you found it difficult (easy) to control your emotions. By that, we mean a situation where you feel that you did not, or experienced difficulties to, successfully manage, change, or control (sucessfully managed, changed, or controlled) your emotions. You might recall a situation when you got carried (managed to not get carried) away by your emotions. Similarly, you might recall a time when you had (no or not much) trouble distracting yourself from or changing your feelings about, and your emotional reactions to a situation" (see De Castella et al., 2018). Participants were asked to describe the recalled situations and to explain how they felt and in what way they found it difficult (had managed) to control or change their emotions.

Participants then answered three manipulation-check items about the situations they had recalled on nine-point scales $(1=$ not at all, $9=$ very much; $\alpha=.84)$ to ensure that those in the low-control (vs. high-control) condition had indeed perceived their emotions as out of (vs. under) control (e.g., "During the situations I recalled, I had little control over my emotions"). 


\section{SELF-CONTROL AND MORALIZATION OF MENTAL STATES}

Subsequently, participants read five different scenarios in a fixed random order, each describing a target entertaining a malevolent thought, including shortened versions of the scenarios used in Studies 1b-2b (see Appendix G). For example, the surgery scenario read:

Brian is a 34-year old man who recently had a leg surgery that required removing some healthy leg tissue to prevent an inflammation. During his stay in the hospital, which he does not like, Brian has thoughts about harming other people, such as the nurses and doctors.

For each scenario, participants answered two items measuring control ascriptions on nine-point scales, adapted from the measure employed in Study 2b (e.g., "Brian is fully capable of choosing his thoughts about harming the hospital personnel," "Brian's thoughts about harming other people are intentional," 1 = completely disagree, $9=$ completely agree . Responses were collapsed for each scenario, and then aggregated across all five scenarios $(\alpha=.83)$. Subsequently, participants completed the same attention check as in Study $2 \mathrm{~b}$ and demographic questions.

\section{Results and Discussion}

Manipulation check. A $t$-test for independent samples confirmed that participants in the low-control condition $(M=7.35, S D=1.59)$ experienced significantly stronger difficulties to control their emotions in the recalled situations compared to those in the high-control condition $(M=3.50, S D=1.77), t(208)=16.60, p<.001$, Cohen's $d=2.29,95 \% \mathrm{CI}_{\mathrm{d}}[1.94,2.64]$.

Control ascriptions. As expected, participants in the low-control condition $(M=6.00$, $S D=1.60)$ ascribed less control to targets over their mental states compared to participants in the high-control condition $(M=6.54, S D=1.54), t(208)=-2.48, p=.014, d=-0.34,95 \% \mathrm{CI}_{\mathrm{d}}[-0.07$, $-0.61]$. 


\section{SELF-CONTROL AND MORALIZATION OF MENTAL STATES}

Complementing studies $3 \mathrm{a}$ and $3 \mathrm{~b}$, these results provide experimental evidence for the idea that the experience of having (versus lacking) control over one's own mental states (i.e., emotions) can impact ascriptions of voluntary control to others over their mental states. Closely following Study $2 b$, the present study focused on capacity of choice and intentionality as central aspects of control (e.g., Monroe et al., 2014). These results emerged across a diverse set of immoral mental states, including mental states differing from one's own (emotional) experiences.

In the SOM (p. 12), we further report a meta-analysis across Study 4a and four additional experimental studies using different manipulations of self-related control perceptions over mental states. Despite mixed results across individual studies, this meta-analysis revealed a small significant experimental effect of perceiving oneself as capable of controlling one's own mental states on control ascriptions to targets over their immoral mental states.

\section{Study $4 b$}

Complementing the results of Study $4 \mathrm{a}$ within a causal-chain framework, Study 4b was designed to test the impact of others' voluntary control over their mental states on moralization. Such a finding would provide complementary experimental evidence in support of our findings from correlational Studies $1 \mathrm{a}-2 \mathrm{~b}$. While a vast body of research documents that controllable immoral actions are condemned more harshly and provoke greater punishment and blame (e.g., Cushman, 2008), to our knowledge, no research thus far has specifically manipulated the degree to which people perceive social targets to have control over their mental states. With respect to the moralization of mental states, prior research has provided correlational, but not experimental, evidence for the role of control ascriptions (Cohen \& Rozin, 2001; Cusimano \& Goodwin, 2019). Therefore, once again drawing on research on free-will beliefs and moral judgment of 


\section{SELF-CONTROL AND MORALIZATION OF MENTAL STATES}

behavior (Monroe et al., 2017), Study 4b manipulated perceptions of targets' control over their mental states and subsequently assessed moralization. We predicted that immoral mental states over which targets have only low (vs. high) control would be moralized less strongly.

\section{Method}

Participants and design. We recruited 211 U.S. American participants on MTurk for a survey on situation perception. They received $\$ 0.35$ as compensation. Twelve participants were excluded because they indicated having answered randomly or purposely wrong (7 individuals), indicated they had participated multiple times in the survey ( 8 individuals), or because they failed an attention check (5 individuals; multiple exclusion criteria possible), resulting in a final $N=199\left(108\right.$ female, 91 male, $\left.M_{\text {age }}=36.47, S D_{\text {age }}=12.00\right)$.

In a within-subject design, all participants saw a total of six scenarios describing a target having an immoral mental state. All scenarios existed in a high-control version (i.e., description of target's control over their mental state as high in 2/6 scenarios; otherwise no explicit mention of control ${ }^{4}$ ) and in a low-control version (i.e., description of target's control over their mental state as impaired in $6 / 6$ scenarios). Each participant saw three of these six scenarios in their highcontrol and three scenarios in their low-control version in an alternating order (within-subject control manipulation). While all participants saw all six scenarios in the identical fixed order, they were randomly assigned to two different versions of the stimulus set: One set started with the high-control version of the first scenario (surgery scenario) and ended with the low-control version of the sixth scenario (affair scenario; see Appendix H). The second set started with the low-control version of the first scenario and ended with the high-control version of the sixth

\footnotetext{
${ }^{4}$ Prior research indicates that people ascribe some degree of control to others over their actions by default (Vohs \& Schooler, 2008), and at least some control over their mental states (Cusimano \& Goodwin, 2019), such that "baseline" control corresponds to high control for the purpose of the present study.
} 


\section{SELF-CONTROL AND MORALIZATION OF MENTAL STATES}

scenario.

Procedure and materials. The high-control versions were mostly identical or highly similar to the scenarios from Study 4a, plus one additional novel scenario (firewood scenario; see Appendix H). In the low-control versions, targets had reduced control over their mental states for various reasons, for instance due to physical or mental disorders (for a similar procedure, see Monroe et al., 2017). For example, in the high-control version of the "surgery scenario" (see Study 4a), participants read that "during his stay in the hospital, which he does not like, Brian has thoughts about harming other people, such as the nurses and doctors. Brian actively produces these thoughts, and he could suppress them, if he wanted." In contrast, in the low-control version, participants read that rather than a leg surgery, the target "recently had brain surgery that required removing some healthy brain tissue to prevent an inflammation. As a result, his thought control is impaired. During his stay in the hospital, which he does not like, Brain has intrusive thoughts about harming other people, such as the nurses and doctors. These thoughts sometimes simply pop into his head, and due to his condition, he can't do anything to supress them." For each scenario, participants completed two moralization items. These assessed moral judgment of the mental state (e.g., "It is morally wrong for Brian to think about harming other people.") and moral blame (e.g., "Brian deserves blame for thinking about harming other people.") on sevenpoint scales $(1=$ completely disagree, $7=$ completely agree $)$. For each scenario version, the two items were collapsed to form two separate indices of moralization across high-control (stimulus set 1: $\alpha=.81$ across scenarios $1,3,5$; stimulus set $2: \alpha=.84$ across scenarios $2,4,6)$ and lowcontrol (stimulus set 1: $\alpha=.74$ across scenarios 2, 4, 6; stimulus set 2: $\alpha=.69$ across scenarios 1 , 3, 5) scenarios. Subsequently, participants again completed an attention-check item asking them to select a certain number on a scale and demographic questions. 
SELF-CONTROL AND MORALIZATION OF MENTAL STATES

\section{Results and Discussion}

Pretest of the manipulation. We conducted a separate pretest to confirm that targets were indeed perceived as having different degrees of control over their mental states in the two scenario versions. For financial reasons, the pretest was appended to an unrelated study. In a between-subjects design, 317 adults (176 females, 141 males, $M_{\text {age }}=34.14, S D_{\text {age }}=9.65$ ) recruited on MTurk saw the six scenarios from the main study either in the high- or the lowcontrol versions (fixed random order). Following each scenario, they completed the two control ascriptions items from Study 4a (1 = completely disagree, 9 = completely agree $)$. Responses were collapsed across items and scenarios to form an index of control ascriptions $(\alpha=.89, M=$ $5.46, S D=2.00)$. Validating the manipulation, a $t$-test for independent samples revealed that participants who saw the low-control versions of the scenarios $(M=4.16, S D=1.52)$ ascribed lower control to the targets than did participants who saw the high-control versions $(M=6.74$, $S D=1.54), t(315)=-14.98, p<.001, d=-1.68,95 \% \mathrm{CI}_{\mathrm{d}}[-1.94,-1.43]$.

Moralization. We conducted a $t$-test for dependent samples on the two moralization scores. As predicted, mental states were moralized less in the case of targets' low $(M=3.37, S D$ $=1.43)$ compared to high $(M=4.46, S D=1.57)$ control, $t(198)=-10.16, p<.001, d_{\mathrm{z}}=-0.72$ 95\% $\mathrm{CI}_{\mathrm{dz}}[-0.88,-0.56]$. Participants thus perceived less moral wrongness and blameworthiness when targets had impaired control over their immoral mental states, across different degrees and sources of impairment.

\section{General Discussion}

The present research investigated individual differences in the moralization of other people's mental states. Our findings suggest that moral reactions to others' mental states are shaped by perceivers' dispositional ability for self-control. Following a regression-based 


\section{SELF-CONTROL AND MORALIZATION OF MENTAL STATES}

approach, four studies established that TSC predicts the moralization of others' mental states, that is, moral judgments of immoral thoughts, inferences about targets' moral character, and blame ascriptions. Studies $1 \mathrm{a}$ and $1 \mathrm{~b}$ found a predictive effect of TSC on the moralization of fantasies about a realistic (Study 1a) or unrealistic (Study 1b) extramarital affair. They further provided initial evidence that this effect was mediated by increased ascriptions of control over mental states to the target. This mediational model remained robust when including additional variables such as perceived likelihood of the target to engage in the immoral behavior (Study 1a) or condemnation of the immoral act (Studies $1 \mathrm{~b}$ and $2 \mathrm{a}$ ). Studies $2 \mathrm{a}$ and $2 \mathrm{~b}$ extended these findings to a different domain, featuring a scenario wherein it was impossible for the target to act upon his thoughts, and a more elaborated measure of control ascriptions based on free-will beliefs research (Study 2b).

Using two additional sets of stimulus materials (comprising a total of 12 different scenarios), Studies 3a-4b more closely examined why individuals high in TSC exhibit heightened control ascriptions, focusing on perceived control over one's own mental states. Employing a self-report scale of emotion-regulation ability, Study 3a suggests that high TSC people ascribe control to others in part because they perceive themselves as capable of changing their feelings via reappraisal. Providing further evidence for the role of self-related control perceptions, Study $3 \mathrm{~b}$ found that the tendency to engage in spontaneous, non-deliberate (vs. deliberate) mind-wandering (i.e., perceiving one's thoughts as uncontrollable) negatively predicted ascriptions of control to others over their immoral mental states. Finally, complementing these correlational findings, Studies $4 \mathrm{a}$ and $4 \mathrm{~b}$ followed a causal-chain approach to mediation, providing experimental evidence for our hypotheses: Individuals induced to perceive difficulties (vs. ease) to control their own mental states (i.e., emotions) ascribed targets 


\section{SELF-CONTROL AND MORALIZATION OF MENTAL STATES}

less control over their diverse immoral mental states (Study 4a). Extending previous and the present correlational studies, Study 4b found that targets' low (vs. high) control over their mental states, in turn, attenuated moralization.

Limitations. The present research employed a large range of realistic stimulus materials. However, the employed scenarios did not systematically differentiate between mental states, and some conflated targets' affective states, attitudes, desires, and mental imagery (cf. Cusimano \& Goodwin, 2019; Guglielmo \& Malle, 2019). Moreover, fictitiousness has been found to exert a stronger attenuating impact on moral judgments of harm compared to those of purity violations (Sabo \& Giner-Sorolla, 2017). As the present scenarios largely focused on desired and imagined harm, future research should thus investigate whether the present findings generalize to other moral foundations (Graham et al., 2013). Speculatively, as intent was found to particularly matter to observers when it comes to harm, the present results may be particularly relevant for harm-related or other-directed transgressions (Chakroff et al., 2015; Young \& Saxe, 2011; see also Young \& Tsoi, 2013; but see Kupfer et al., 2020). In a similar vein, the present research exclusively focused on proscriptive (vs. prescriptive) morality. In a recent study (Cusimano \& Goodwin, 2019, Study 6), judgments of targets' intentionality and the ability to stop their positive mental states predicted responsibility ascriptions and/or character inferences. Hence, further research should examine whether the effects of TSC via control ascriptions extend to praiseworthy thoughts. Given the intercultural variation in the degree to which intentions matter for moral judgment (Barrett et al., 2016), intercultural replications are furthermore desirable. On a related note, the present studies did not differentiate between different aspects of control (e.g., capacity of choice; intentionality), in line with prior theoretical conceptualizations and empirical findings of these as closely interrelated (e.g., Cusimano \& Goodwin, 2019). Rather, they yielded 


\section{SELF-CONTROL AND MORALIZATION OF MENTAL STATES}

consistent results across different operationalizations of ascribed control.

Notably, similar to other work investigating correlates of TSC, the present study designs are mostly correlational in nature, and rely on a single — but validated and widely used — selfreport scale (Tangney et al., 2004). Yet, results appear robust across diverse stimulus materials and populations. The present studies furthermore ruled out potential confounds (e.g., behavior condemnation; behavior likelihood) and integrated validated measures of theoretically relevant variables (i.e., emotion regulation; mind-wandering) in our models. The differential effects for theoretically more (vs. less, i.e., expressive suppression, deliberate mind-wandering; Studies 3a3b) relevant facets of the investigated constructs enhances confidence in the validity of our interpretations, rendering it implausible that the present effects should be attributable to general response biases, or consistent or socially desirable responding.

We also sought complementary experimental evidence for our model. Study $4 \mathrm{a}$ is suggestive of an experimental effect of self-related control perceptions on control ascriptions to others. However, it appears difficult to manipulate people's overall sense of "mental control" in a subtle manner while finding evidence for the predicted experimental effect (see SOM). More blatant manipulations such as the one used in Study 4a may, however, be susceptible to demand effects - even though the diversity of scenarios and mental states involved in our experimental studies likely obscured the study objective to participants. In Study 4b, the manipulation of reduced target control may likewise appear relatively blatant in some of the scenarios. However, this is to our knowledge the first study to experimentally investigate the effect of control ascriptions on moral judgments of mental states. For this reason, we opted for a relatively strong manipulation, which matches stimulus materials used in prior work on behavior judgments (e.g., Martin \& Cushman, 2016; Monroe et al., 2017). 
SELF-CONTROL AND MORALIZATION OF MENTAL STATES

\section{Theoretical Contributions}

Contributions to research on moral judgment. A large body of evidence supports a person-centered view on moral judgment - the notion that moral judgments track information about a person's character rather than merely (outcomes of) behavior (e.g., Pizarro \& Tannenbaum, 2011; Uhlmann et al., 2015; Uhlmann et al., 2013). More generally, lay people tend to ascribe a special quality to the mind and distinguish it from observable features of the environment including overt behavior (Burgmer \& Forstmann, 2018; Forstmann \& Burgmer, $2015,2017)$. Yet, only little research has directly investigated moral perceptions of purely mental states in absence of any manifest consequences or communicative intent (e.g., Cohen \& Rozin, 2001; Gromet et al., 2016; Sabo \& Giner-Sorolla, 2017). The present studies indicate that people's purely internal, "private" mental activities are nevertheless perceived as informative and diagnostic in and of themselves, and have detrimental consequences in terms of one's (im)moral reputation.

Moreover, only few studies thus far have addressed perceptions of voluntary control over mental states as an antecedent of moral reactions (Cohen \& Rozin, 2001; Cusimano \& Goodwin, 2019). Using both existing and novel materials, the present research links this prior work with theoretically relevant interindividual differences, while considering behavior-related appraisals (e.g., likelihood perceptions; see also Cohen \& Rozin, 2001). Critically, to our knowledge, the present research is the first to provide experimental evidence for an effect of control ascriptions on moralization of mental states. It thereby extends research demonstrating that agents' control over their overt behavior affects moral judgments and blame and evokes more negative character judgments (Alicke, 2000; Monroe et al., 2017). The present studies thus underline that the 


\section{SELF-CONTROL AND MORALIZATION OF MENTAL STATES}

processes via which targets arrive at their mental states matter strongly to observers when making social judgments (see also Rom et al., 2017).

Furthermore, the present findings suggest that egocentric projection may play a critical role in the moral judgment of mental states, and moral judgment more broadly. Moral wrongness and blameworthiness judgments are known to be affected by perceived outcomes such as the harm they caused or the assessment of whether a norm was violated (e.g., Cushman, 2008; Malle, 2020; Patil et al., 2017). However, they are also critically shaped by inferences about agents' mental states such as their intentions or justifying reasons and by mental or physical preventability as aspects of control (e.g., Malle, 2020). In line with the idea that nonmoral and moral judgments rely on the same cognitive processes (Knobe, 2018), perceivers, who lack direct access to others' minds, may thus rely on processes of mental-state inference which in turn partially draw on egocentric information (Birch \& Bloom, 2007; Epley \& Caruso, 2004; Epley et al., 2004; Van Boven \& Loewenstein, 2003). Particularly moral judgments of mental states —as opposed to overt behavior - may be biased in this way, because outcome and harm assessments are less available or applicable and because control relates to mental processes. Notably, from a reputational perspective, it may be beneficial to take egocentric information into account by simulating oneself in the moral situation: In addition to corresponding to social norms shared within their community, people's moral judgments should be calibrated to their own "moral performance" to avoid the negative impression of hypocrisy (Jordan et al., 2018).

Finally, prior work has related interindividual differences to moral judgment (e.g., Bartels \& Pizarro, 2011; Burgmer et al., 2019; Byrd \& Conway, 2019; Conway et al., 2018;

Gleichgerrcht \& Young, 2013; Inbar et al., 2009; Koenigs et al., 2014; Koerner et al., 2020; Miller et al., 2014; Weiss et al., 2018). Much of this work, however, has focused on "classic" 


\section{SELF-CONTROL AND MORALIZATION OF MENTAL STATES}

moral dilemma decisions and individual differences in affective reactions to them. With TSC, the present studies address an important and impactful, but previously neglected interindividual difference variable in relation to moral cognition, more broadly. They furthermore shed light on the processes involved by including validated measures of people's self-perceived (mental) control, bridging literatures as diverse as self-control, metacognition, egocentric projection, and moral judgment.

Contributions to self-control research. Our findings with regard to mediators of the observed effect support the previously proposed relationship between self-control and an enhanced belief in free will (Baumeister, 2008; Baumeister \& Brewer, 2012). Moreover, the present research provides novel insights into the interplay between self-control and moralitytwo domains that have been treated separately by and large despite their obvious connection (see Baumeister \& Alghamdi, 2015; Hofmann et al., 2018). To our knowledge, the present studies provide the first empirical evidence that high TSC individuals do not only behave more in line with moral norms (e.g., de Ridder et al., 2012), but that they also hold others to stricter moral standards than low TSC individuals_—when judging their mental states, and also their behavior (see Studies 1b-2a; Study 2c, SOM). While one might have expected high TSC individuals to have lower expectations of others' morality in light of their own "superior morality," the current findings are more in line with a self-projection account. The present studies thereby show how people's own self-control ability may not only shape performance or self-perception, but also social perception. Moreover, whereas a wealth of research has documented and emphasized the positive intraindividual and social effects of high self-control, there is only very little research on potential detrimental consequences of self-control, for example on some aspects of interpersonal relationships (but see Koval et al., 2015). 


\section{SELF-CONTROL AND MORALIZATION OF MENTAL STATES}

Beyond its relation to moral judgment, the present results also contribute to our theoretical understanding of TSC and what distinguishes people with high (vs. low) TSC (e.g., Baumeister et al., 2019; Saunders et al., 2018). Under a conceptualization of self-control as primarily behavioral inhibition, one may alternatively have expected high-TSC individuals to focus on people's overt behavior, and simply not care about immoral mental states. In contrast, our findings underscore that TSC includes the regulation of inner states (Tangney et al., 2004). They thereby buttress recent findings and theorizing on the complex processes underlying high TSC individuals' achievements (e.g., Duckworth et al., 2016; Fujita, 2011; Gillebaart \& de Ridder, 2015; Hofmann et al., 2012; Hofmann \& Kotabe, 2012; Katzir et al., 2021; Nilsen et al., 2020).

\section{Open Questions and Implications}

The present research bears a number of open questions and noteworthy implications. First, despite consistent support for the role of control ascriptions, additional variables may play a role in moralization and how it is shaped by self-control. However, evidence for the role of behavior condemnation, as one potential candidate, was inconsistent, and a thorough investigation is beyond the scope of the present research. In a similar vein, the present research did not investigate the impact of targets' actual, ultimate behaviors. In prior studies, targets who behaved virtuously in overcoming a conflicting immoral desire were perceived particularly positively, at least by adults (Starmans \& Bloom, 2016). The present studies extend these findings, underlining that when targets cannot or do not show any related behavior, their immoral mental states elicit harsh reactions_-particularly in those who typically show restraint in behavior themselves. The perceived likelihood that a target will act upon their thoughts positively predicted moralization when included in two of our studies (Study 1a; Study 1c, SOM, 


\section{SELF-CONTROL AND MORALIZATION OF MENTAL STATES}

p. 5), complementing prior work on the effects of beliefs about a deterministic relationship between thoughts and behavior on behavior judgment (Plaks et al., 2009). Some recent work has emphasized the association between TSC and the effective use of strategies to avoid temptations in the first place rather than constantly fighting them (Ent et al., 2015; Fujita et al., 2018; Gillebaart \& DeRidder, 2015; Hofmann et al., 2012; Imhoff et al., 2014). Nevertheless, likelihood perceptions of the target to pursue the tempting course of action emerged only as a secondary mediator of the effects of TSC or were negatively related to it in the present studies.

Furthermore, the present studies did not examine whether individuals with high TSC hold their own inner life to the same strict moral standards as others'. Speaking to this notion, a previous study indicates that the degree to which people require themselves to effortfully control their inappropriate emotions is linked to self-reported anger at their emotional reactions (Mitmansgruber et al., 2009). Yet, more research is needed connecting self-perceptions of controllability with self-directed moralization, and potential implications for self-control efficiency (see also Hofmann et al., 2018).

Lastly, the present research focused on social perception, which may nevertheless have behavioral implications. Moralizing another's mental states may motivate people to avoid them (Uhlmann et al., 2016), or possibly otherwise express disapproval. Yet, when and how high TSC individuals openly express their harsher moral reactions remains an open question. As expressing blame or punishing others may entail negative consequences (e.g., Anderson et al., 2020; Voiklis \& Malle, 2018), and people are often reluctant to punish (e.g., Xiao \& Hauser, 2008), highly self-controlled individuals may contain themselves and not express their disapproval at all, or opt for rather subtle and socially accepted behavioral reactions such as gossiping or simply avoiding targets. Nevertheless, interindividual differences in the moralization of mental states certainly 


\section{SELF-CONTROL AND MORALIZATION OF MENTAL STATES}

bear potential for interpersonal conflict, especially when people are unaware of the impression they convey when disclosing their malevolent, but "harmless" thoughts and desires to others. 


\section{SELF-CONTROL AND MORALIZATION OF MENTAL STATES}

\section{Acknowledgments}

This research was funded through a junior start-up grant awarded to Alexa Weiss by the Center for Social and Economic Behavior at the University of Cologne, Germany. We thank Stephanie Wolf for collecting the data for Study 3b. We thank Wilhelm Hofmann for feedback on a previous version of this manuscript. 
SELF-CONTROL AND MORALIZATION OF MENTAL STATES

\section{References}

Abler, B., \& Kessler, H. (2009). Emotion regulation questionnaire - Eine deutschsprachige Fassung des ERQ von Gross und John. Diagnostica, 55(3), 144-152. https://doi.org/10.1026/0012-1924.55.3.144

Adams, R. (1976). Motive utilitarianism. The Journal of Philosophy, 73(14), 467-481. https://doi.org/10.2307/2025783

Alicke, M. D. (2000). Culpable control and the psychology of blame. Psychological Bulletin, 126(4), 556-574. https://doi.org/10.1037/0033-2909.126.4.556

Allen, T. J., Moeller, F. G., Rhoades, H. M., \& Cherek, D. R. (1998). Impulsivity and history of drug dependence. Drug and Alcohol Dependence, 50(2), 137-145. https://doi.org/10.1016/S0376-8716(98)00023-4

Ames, D. R., \& Johar, G. V. (2009). I'll know what you're like when I see how you feel: How and when affective displays influence behavior-based impressions. Psychological Science, 20(5), 586-593. https://doi.org/10.1111/j.1467-9280.2009.02330.x

Anderson, R. A., Crockett, M. J., \& Pizarro, D. A. (2020). A theory of moral praise. Trends in Cognitive Sciences 24(9), 694-703. https://doi.org/10.1016/j.tics.2020.06.008

Barrett, H. C., Bolyanatz, A., Crittenden, A. N., Fessler, D. M. T., Fitzpatrick, S., Gurven, M., Henrich, J., Kanovsky, M., Kushnick, G., Pisor, A., Scelza, B. A., Stich, S., von Rueden, C., Zhao, W., \& Laurence, S. (2016). Small-scale societies exhibit fundamental variation in the role of intentions in moral judgment. Proceedings of the National Academy of Sciences, 113(17), 4688-4693. https://doi.org/10.1073/pnas.1522070113 
SELF-CONTROL AND MORALIZATION OF MENTAL STATES

Bartels, D. M., \& Pizarro, D. A. (2011). The mismeasure of morals: Antisocial personality traits predict utilitarian responses to moral dilemmas. Cognition, 121(1), 154-161. https://doi.org/10.1016/j.cognition.2011.05.010

Baumeister, R. F. (2008). Free will in scientific psychology. Perspectives on Psychological Science, 3(1), 14-19. https://doi.org/10.1111/j.1745-6916.2008.00057.x

Baumeister, R. F., \& Alghamdi, N. G. (2015). Role of self-control failure in immoral and unethical actions. Current Opinion in Psychology, 6, 66-69. https://doi.org/10.1016/j.copsyc.2015.04.001

Baumeister, R. F., \& Brewer, L. E. (2012). Believing versus disbelieving in free will: Correlates and consequences. Social and Personality Psychology Compass, 6(10), 736-745. https://doi.org/10.1111/j.1751-9004.2012.00458.x

Baumeister, R. F., \& Exline, J. (1999). Virtue, personality, and social relations: Self-control as the moral muscle. Journal of Personality, 67(6), 1165-1194. https://doi.org/10.1111/1467-6494.00086

Baumeister, R. F., Heatherton, T. F., \& Tice, D. M. (1994). Losing control: How and why people fail at self-regulation. Academic Press.

Baumeister, R. F., Vohs, K. D., \& Tice, D. M. (2007). The strength model of self-control. Current Directions in Psychological Science, 16(6), 351-355. https://doi.org/10.1111/j.1467-8721.2007.00534.x

Baumeister, R. F., Wright, B. R., \& Carreon, D. (2019). Self-control "in the wild": Experience sampling study of trait and state self-regulation. Self and Identity, 18(5), 494-528. https://doi.org/10.1080/15298868.2018.1478324 
SELF-CONTROL AND MORALIZATION OF MENTAL STATES

Bertrams, A., \& Dickhäuser, O. (2009). Messung dispositioneller Selbstkontroll-Kapazität: Eine deutsche Adaptation der Kurzform der Self-Control Scale (SCS-KD). Diagnostica, 55(1), 2-10. https://doi.org/10.1026/0012-1924.55.1.2

Birch, S. A., \& Bloom, P. (2007). The curse of knowledge in reasoning about false beliefs. Psychological Science, 18(5), 382-386. https://doi.org/10.1111/j.14679280.2007.01909.x

Bolin, A. U. (2004). Self-control, perceived opportunity, and attitudes as predictors of academic dishonesty. The Journal of Psychology, 138(2), 101-114. https://doi.org/10.3200/JRLP.138.2.101-114

Burgmer, P., \& Forstmann, F. (2018). Mind-body dualism and health revisited: How belief in dualism shapes health behavior. Social Psychology, 49, 219-230. https://doi.org/10.1027/1864-9335/a000344

Burgmer, P., Weiss, A., \& Ohmann, K. (2019). I don't feel ya: How narcissism shapes empathy. Self and Identity, 20(2), 199-215. https://doi.org/10.1080/15298868.2019.1645730

Byrd, N., \& Conway, P. (2019). Not all who ponder count costs: Arithmetic reflection predicts utilitarian tendencies, but logical reflection predicts both deontological and utilitarian tendencies. Cognition, 192, Article 103995. https://doi.org/10.1016/j.cognition.2019.06.007

Carriere, J. S. A., Seli, P., \& Smilek, D. (2013). Wandering in both mind and body: Individual differences in mind wandering and inattention predict fidgeting. Canadian Journal of Experimental Psychology, 67(1), 19-31. https://doi.org/10.1037/a0031 438

Chakroff, A., Dungan, J., Koster-Hale, J., Brown, A., Saxe, R., \& Young, L. (2015). When minds matter for moral judgment: Intent information is neurally encoded for harmful but 
SELF-CONTROL AND MORALIZATION OF MENTAL STATES

not impure acts. Social Cognitive and Affective Neuroscience, 11(3), 476-484. https://doi.org/10.1093/scan/nsv131

Cohen, A. B. (2003). Religion, likelihood of action, and the morality of mentality. International Journal for the Psychology of Religion, 13(4), 273-285. https://doi.org/10.1207/S15327582IJPR1304_4

Cohen, A. B., \& Rankin, A. (2004). Religion and the morality of positive mentality. Basic and Applied Social Psychology, 26(1), 45-57. https://doi.org/10.1207/s15324834basp2601_5

Cohen, A. B., \& Rozin, P. (2001). Religion and the morality of mentality. Journal of Personality and Social Psychology, 81(4), 697-710. https://doi.org/10.1037/0022-3514.81.4.697

Conway, P., Goldstein-Greenwood, J., Polacek, D., \& Greene, J. D. (2018). Sacrificial utilitarian judgments do reflect concern for the greater good: Clarification via process dissociation and the judgments of philosophers. Cognition, 179, 241-265. https://doi.org/10.1016/j.cognition.2018.04.018

Critcher, C. R., Inbar, Y., \& Pizarro, D. A. (2013). How quick decisions illuminate moral character. Social Psychological and Personality Science, 4(3), 308-315. https://doi.org/10.1177/1948550612457688

Cushman, F. (2008). Crime and punishment: Distinguishing the roles of causal and intentional analyses in moral judgment. Cognition, 108(2), 353-380. https://doi.org/10.1016/j.cognition.2008.03.006

Cusimano, C., \& Goodwin, G. P. (2019). Lay beliefs about the controllability of everyday mental states. Journal of Experimental Psychology: General, 148(10), 1701-1732. https://doi.org/10.1037/xge0000547 
SELF-CONTROL AND MORALIZATION OF MENTAL STATES

De Castella, K., Platow, M. J., Tamir, M., \& Gross, J. J. (2018). Beliefs about emotion: Implications for avoidance-based emotion regulation and psychological health. Cognition and Emotion, 32(4), 773-795. https://doi.org/10.1080/02699931.2017.1353485

de Ridder, D. T. D., Kroese, F., \& Gillebaart, M. (2018). Whatever happened to self-control? A proposal for integrating notions from trait self-control studies into state self-control research. Motivation Science, 4(1), 39-49. https://doi.org/10.1037/mot0000062

de Ridder, D. T. D., Lensvelt-Mulders, G., Finkenauer, C., Stok, F. M., \& Baumeister, R. F. (2012). Taking stock of self-control. Personality and Social Psychology Review, 16(1), 76-99. https://doi.org/10.1177/1088868311418749

Denson, T. F., DeWall, C. N., \& Finkel, E. J. (2012). Self-Control and aggression. Current Directions in Psychological Science, 21(1), 20-25. https://doi.org/10.1177/0963721411429451

Duckworth, A. L., Gendler, T. S., \& Gross, J. J. (2016). Situational strategies for self-control. Perspectives on Psychological Science, 11(1), 35-55. https://doi.org/10.1177/1745691615623247

Ent, M. R., Baumeister, R. F., \& Tice, D. M. (2015). Trait self-control and the avoidance of temptation. Personality and Individual Differences, 74, 12-15. https://doi.org/10.1016/j.paid.2014.09.031

Epley, N., \& Caruso, E. M. (2004). Egocentric ethics. Social Justice Research, 17(2), 171-187. https://doi.org/10.1023/B:SORE.0000027408.72713.45

Epley, N., Keysar, B., Van Boven, L., \& Gilovich, T. (2004). Perspective taking as egocentric anchoring and adjustment. Journal of Personality and Social Psychology, 87(3), 327-339. https://doi.org/10.1037/0022-3514.87.3.327 


\section{SELF-CONTROL AND MORALIZATION OF MENTAL STATES}

Feldman, G., Baumeister, R. F., \& Wong, K. F. E. (2014). Free will is about choosing: The link between choice and the belief in free will. Journal of Experimental Social Psychology, 55, 239-245. https://doi.org/10.1016/j.jesp.2014.07.012

Fishbach, A., \& Woolley, K. (2015). Avoiding ethical temptations. Current Opinion in Psychology, 6, 36-40. https://doi.org/10.1016/j.copsyc.2015.03.019

Forstmann, M., \& Burgmer, P. (2015). Adults are intuitive mind-body dualists. Journal of Experimental Psychology: General, 144, 222-235. https://doi.org/10.1037/xge0000045

Forstmann, M., \& Burgmer, P. (2017). Antecedents, manifestations, and consequences of belief in mind-body dualism. In C. M. Zedelius, B. C. Müller, \& J. W. Schooler (Eds.), The science of lay theories (pp. 181-205). Springer. https://doi.org/10.1007/978-3-31957306-9_8

Fujita, K. (2011). On conceptualizing self-control as more than the effortful inhibition of impulses. Personality and SocialPpsychology Review, 15(4), 352-366. https://doi.org/10.1177/1088868311411165

Fujita, K., Carnevale, J. J., \& Trope, Y. (2018). Understanding self-control as a whole vs. part dynamic. Neuroethics, 11(3), 283-296. https://doi.org/10.1007/s12152-016-9250-2

Giambra, L. M. (1995). A laboratory method for investigating influences on switching attention to task-unrelated imagery and thought. Consciousness and Cognition: An International Journal, 4(1), 1-21. https://doi.org/10.1006/ccog.1995.1001

Gillebaart, M., \& de Ridder, D. T. D. (2015). Effortless self-control: A novel perspective on response conflict strategies in trait self-control. Social and Personality Psychology Compass, 9(2), 88-99. https://doi.org/10.1111/spc3.12160 


\section{SELF-CONTROL AND MORALIZATION OF MENTAL STATES}

Gillebaart, M., Schneider, I. K., \& de Ridder, D. T. (2016). Effects of trait self-control on response conflict about healthy and unhealthy food. Journal of Personality, 84(6), 789798. https://doi.org/10.1111/jopy.12219

Gino, F., Schweitzer, M. E., Mead, N. L., \& Ariely, D. (2011). Unable to resist temptation: How self-control depletion promotes unethical behavior. Organizational Behavior and Human Decision Processes, 115(2), 191-203. https://doi.org/10.1016/J.OBHDP.2011.03.001

Gleichgerrcht, E., \& Young, L. (2013). Low levels of empathic concern predict utilitarian moral judgment. PLoS ONE, 8(4), Article e60418. https://doi.org/10.1371/journal.pone.0060418

Gottfredson, M. R., \& Hirschi, T. (1990). A general theory of crime. Stanford University Press.

Graham, J., Haidt, J., Koleva, S., Motyl, M., Iyer, R., Wojcik, S. P., \& Ditto, P. H. (2013). Moral foundations theory: The pragmatic validity of moral pluralism. Advances in Experimental Social Psychology, 47, 55-130. https://doi.org/10.1016/B978-0-12-407236-7.00002-4

Gromet, D. M., Goodwin, G. P., \& Goodman, R. A. (2016). Pleasure from another's pain. Personality and Social Psychology Bulletin, 42(8), 1077-1091. https://doi.org/10.1177/0146167216651408

Gross, J. J., \& John, O. P. (2003). Individual differences in two emotion regulation processes: Implications for affect, relationships, and well-being. Journal of Personality and Social Psychology, 85(2), 348-362. https://doi.org/10.1037/0022-3514.85.2.348

Guglielmo, S., \& Malle, B. F. (2019). Asymmetric morality: Blame is more differentiated and more extreme than praise. PLoS ONE, 14(3), e0213544. https://doi.org/10.1371/journal.pone.0213544 


\section{SELF-CONTROL AND MORALIZATION OF MENTAL STATES}

Hare, T. A., Camerer, C. F., \& Rangel, A. (2009). Self-control in decision-making involves modulation of the vmPFC valuation system. Science, 324(5927), 646-648. https://doi.org/10.1126/science. 1168450

Hofmann, W., Baumeister, R. F., Förster, G., \& Vohs, K. D. (2012). Everyday temptations: An experience sampling study of desire, conflict, and self-control. Journal of Personality and Social Psychology, 102(6), 1318-1335. https://doi.org/10.1037/a0026545

Hofmann, W., Friese, M., \& Strack, F. (2009). Impulse and self-control from a dual-systems perspective. Perspectives on Psychological Science, 4(2), 162-176. https://doi.org/10.1111/j.1745-6924.2009.01116.x

Hofmann, W., Meindl, P., Mooijman, M., \& Graham, J. (2019). Morality and self-control: How they are intertwined, and where they differ. Current Directions in Psychological Science, 27(4), 286-291. https://doi.org/10.1177/0963721418759317

Hofmann, W., Schmeichel, B. J., \& Baddeley, A. D. (2012). Executive functions and selfregulation. Trends in Cognitive Sciences, 16(3), 174-180. https://doi.org/10.1016/J.TICS.2012.01.006

Imhoff, R., Schmidt, A. F., \& Gerstenberg, F. (2014). Exploring the interplay of trait self-control and ego depletion: Empirical evidence for ironic effects. European Journal of Personality, 28(5), 413-424. https://doi.org/10.1002/per.1899

Inbar, Y., Pizarro, D. A., \& Cushman, F. (2012). Benefiting from misfortune. Personality and Social Psychology Bulletin, 38(1), 52-62. https://doi.org/10.1177/0146167211430232

Inbar, Y., Pizarro, D. A., Knobe, J., \& Bloom, P. (2009). Disgust sensitivity predicts intuitive disapproval of gays. Emotion, 9(3), 435-439. https://doi.org/10.1037/a0015960 


\section{SELF-CONTROL AND MORALIZATION OF MENTAL STATES}

Inzlicht, M., Bartholow, B. D., \& Hirsh, J. B. (2015). Emotional foundations of cognitive control. Trends in Cognitive Sciences, 19(3), 126-132. https://doi.org/10.1016/j.tics.2015.01.004

Inzlicht, M., \& Berkman, E. (2015). Six questions for the resource model of control (and some answers). Social and Personality Psychology Compass, 9(10), 511-524. https://doi.org/10.1111/spc3.12200

Inzlicht, M., \& Legault, L. (2014). No pain, no gain: How distress underlies effective self-control (and unites diverse social psychological phenomena). In J. Forgas \& E. Harmon-Jones (Eds.), The control within: Motivation and its regulation (pp. 115-132). Psychology Press.

Jordan, J. J., Sommers, R., Bloom, P., \& Rand, D. G. (2017). Why do we hate hypocrites? Evidence for a theory of false signaling. Psychological Science, 28(3), 356-368. https://doi.org/10.1177/0956797616685771

Katzir, M., Baldwin, M., Werner, K., \& Hofmann, W. (2021). Moving beyond inhibition: Capturing a broader scope of the self-control construct with the Self-Control Strategy Scale (SCSS) [Manuscript under review]. Interdisciplinary Studies Unit, Bar Ilan University.

Kenrick, D. T. (2011). Sex, murder, and the meaning of life: A psychologist investigates how evolution, cognition, and complexity are revolutionizing our view of human nature. Basic Books.

Knobe, J. (2018). There is no important distinction between moral and nonmoral cognition. In K. J. Gray \& J. Graham (Eds.), Atlas of moral psychology (pp. 556-564). Guilford Press. 


\section{SELF-CONTROL AND MORALIZATION OF MENTAL STATES}

Koenigs, M., Kruepke, M., Zeier, J., \& Newman, J. P. (2012). Utilitarian moral judgment in psychopathy. Social Cognitive and Affective Neuroscience, 7(6), 708-714. https://doi.org/10.1093/scan/nsr048

Körner, A., Deutsch, R., \& Gawronski, B. (2020). Using the CNI model to investigate individual differences in moral dilemma judgments. Personality and Social Psychology Bulletin, 46(9), 1392-1407. https://doi.org/10.1177/0146167220907203

Kotabe, H. P., \& Hofmann, W. (2015). On integrating the components of self-control. Perspectives on Psychological Science, 10(5), 618-638. https://doi.org/10.1177/1745691615593382

Koval, C. Z., vanDellen, M. R., Fitzsimons, G. M., \& Ranby, K. W. (2015). The burden of responsibility: Interpersonal costs of high self-control. Journal of Personality and Social Psychology, 108(5), 750-766. https://doi.org/10.1037/pspi0000015

Krueger, J., \& Clement, R. W. (1994). The truly false consensus effect: an ineradicable and egocentric bias in social perception. Journal of Personality and Social Psychology, 67(4), 596-610. https://doi.org/10.1037/0022-3514.67.4.596

Kupfer, T. R., Inbar, Y., \& Tybur, J. M. (2020). Reexamining the role of intent in moral judgements of purity violations. Journal of Experimental Social Psychology, 91, Article 104043. https://doi.org/10.1016/j.jesp.2020.104043

Malle, B. F. (2021). Moral judgments. Annual Review of Psychology, 72, 293-318. https://doi.org/10.1146/annurev-psych-072220-104358

Malle, B. F., Guglielmo, S., \& Monroe, A. E. (2014). A theory of blame. Psychological Inquiry, 25(2), 147-186. https://doi.org/10.1080/1047840X.2014.877340 


\section{SELF-CONTROL AND MORALIZATION OF MENTAL STATES}

Malle, B. F., \& Knobe, J. (1997). The folk concept of intentionality. Journal of Experimental Social Psychology, 33(2), 101-121. https://doi.org/10.1006/jesp.1996.1314

Malouf, E. T., Schaefer, K. E., Witt, E. A., Moore, K. E., Stuewig, J., \& Tangney, J. P. (2014). The brief self-control scale predicts jail inmates' recidivism, substance dependence, and post-release adjustment. Personality and Social Psychology Bulletin, 40(3), 334-347. https://doi.org/10.1177/0146167213511666

Martin, J. W., \& Cushman, F. (2016). Why we forgive what can't be controlled. Cognition, 147, 133-143. https://doi.org/10.1016/j.cognition.2015.11.008

Martin, N. D., Rigoni, D., \& Vohs, K. D. (2017). Free will beliefs predict attitudes toward unethical behavior and criminal punishment. Proceedings of the National Academy of Sciences, 114, 7325-7330. https://doi.org/10.1073/pnas.1702119114

Mead, N. L., Baumeister, R. F., Gino, F., Schweitzer, M. E., \& Ariely, D. (2009). Too tired to tell the truth: Self-control resource depletion and dishonesty. Journal of Experimental Social Psychology, 45(3), 594-597. https://doi.org/10.1016/j.jesp.2009.02.004

Miller, R. M., Hannikainen, I. A., \& Cushman, F. A. (2014). Bad actions or bad outcomes? Differentiating affective contributions to the moral condemnation of harm. Emotion, 14(3), 573-587. https://doi.org/10.1037/a0035361.

Monroe, A. E., Brady, G. L., \& Malle, B. F. (2017). This isn’t the free will worth looking for. Social Psychological and Personality Science, 8(2), 191-199. https://doi.org/10.1177/1948550616667616

Monroe, A. E., Dillon, K. D., \& Malle, B. F. (2014). Bringing free will down to Earth: People’s psychological concept of free will and its role in moral judgment. Consciousness and Cognition, 27, 100-108. https://doi.org/10.1016/J.CONCOG.2014.04.011 


\section{SELF-CONTROL AND MORALIZATION OF MENTAL STATES}

Monroe, A. E., \& Malle, B. F. (2010). From uncaused will to conscious choice: The need to study, not speculate about people's folk concept of free will. Review of Philosophy and Psychology, 1, 211-224. https://doi.org/10.1007/s13164-009-0010-7

Monroe, A. E., \& Malle, B. F. (2017). Two paths to blame: Intentionality directs moral information processing along two distinct tracks. Journal of Experimental Psychology: General, 146(1), 123-133. https://doi.org/10.1037/xge0000234

Morewedge, C. K., Giblin, C. E., \& Norton, M. I. (2014). The (perceived) meaning of spontaneous thoughts. Journal of Experimental Psychology: General, 143(4), 17421754. https://doi.org/10.1037/a0036775

Mrazek, M. D., Phillips, D. T., Franklin, M. S., Broadway, J. M., \& Schooler, J. W. (2013). Young and restless: Validation of the Mind-Wandering Questionnaire (MWQ) reveals disruptive impact of mind-wandering for youth. Frontiers in Psychology, 4, Article 560. https://doi.org/10.3389/fpsyg.2013.00560

Nahmias, E., \& Thompson, M. (2014). A naturalistic vision of free will. In E. Machery \& E. O’Neill (Eds.), Current controversies in experimental philosophy (pp. 86-103). Routledge.

Nilsen, F. A., Bang, H., Boe, O., Martinsen, Ø. L., Lang-Ree, O. C., \& Røysamb, E. (2020). The Multidimensional Self-Control Scale (MSCS): Development and validation. Psychological Assessment, 32(11), 1057-1074. https://doi.org/10.1037/pas0000950

Paschke, L. M., Dörfel, D., Steimke, R., Trempler, I., Magrabi, A., Ludwig, V. U., Schubert, T., Stelzel, C., \& Walter, H. (2016). Individual differences in self-reported self-control 
SELF-CONTROL AND MORALIZATION OF MENTAL STATES

predict successful emotion regulation. Social Cognitive and Affective Neuroscience, 11(8), 1193-1204. https://doi.org/10.1093/scan/nsw036

Patil, I., Calò, M., Fornasier, F., Cushman, F., \& Silani, G. (2017). The behavioral and neural basis of empathic blame. Scientific Reports, 7, Article 5200. https://doi.org/10.1038/s41598-017-05299-9

Pizarro, D. A., \& Tannenbaum, D. (2011). Bringing character back: How the motivation to evaluate character influences judgments of moral blame. In M. Mikulincer \& P. R. Shaver (Eds.), The social psychology of morality: Exploring the causes of good and evil (pp. 91-108). American Psychological Association. https://doi.org/10.1037/13091-005

Pizarro, D., Uhlmann, E., \& Salovey, P. (2003). Asymmetry in judgments of moral blame and praise: The role of perceived metadesires. Psychological Science, 14(3), 267-272. https://doi.org/10.1111/1467-9280.03433

Plaks, J. E., McNichols, N. K., \& Fortune, J. L. (2009). Thoughts versus deeds: Distal and proximal intent in lay judgments of moral responsibility. Personality and Social Psychology Bulletin, 35(12), 1687-1701. https://doi.org/10.1177/0146167209345529

Rom, S. C., Weiss, A., \& Conway, P. (2017). Judging those who judge: Perceivers infer the roles of affect and cognition underpinning others' moral dilemma responses. Journal of Experimental Social Psychology, 69, 44-58. https://doi.org/10.1016/j.jesp.2016.09.007

Ross, L., Greene, D., \& House, P. (1977). The "false consensus effect": An egocentric bias in social perception and attribution processes. Journal of Experimental Social Psychology, 13(3), 279-301. https://doi.org/10.1016/0022-1031(77)90049-X

Rosseel, Y. (2012). Lavaan: An R package for structural equation modeling and more. Version 0.5- 12 (BETA). Journal of Statistical Software, 48, 1-36. 
SELF-CONTROL AND MORALIZATION OF MENTAL STATES

Sabo, J. S., \& Giner-Sorolla, R. (2017). Imagining wrong: Fictitious contexts mitigate condemnation of harm more than impurity. Journal of Experimental Psychology: General, 146(1), 134-153. https://doi.org/10.1037/xge0000251

Saunders, B., Milyavskaya, M., Etz, A., Randles, D., \& Inzlicht, M. (2018). Reported selfcontrol is not meaningfully associated with inhibition-related executive function: A Bayesian analysis. Collabra: Psychology, 4(1), Article 39. https://doi.org/10.1525/collabra.134

Schooler, J. W., Smallwood, J., Christoff, K., Handy, T. C., Reichle, E. D., \& Sayette, M. A. (2011). Meta-awareness, perceptual decoupling and the wandering mind. Trends in Cognitive Sciences, 15(7), 319-326. https://doi.org/10.1016/j.tics.2011.05.006

Schönbrodt, F. D., \& Perugini, M. (2013). At what sample size do correlations stabilize? Journal of Research in Personality, 47(5), 609-612. https://doi.org/10.1016/j.jrp.2013.05.009

Schubert, A. L., Frischkorn, G. T., \& Rummel, J. (2020). The validity of the online thoughtprobing procedure of mind wandering is not threatened by variations of probe rate and probe framing. Psychological Research, 84, 1846-1856. https://doi.org/10.1007/s00426019-01194-2

Shariff, A. F., Greene, J. D., Karremans, J. C., Luguri, J. B., Clark, C. J., Schooler, J. W., ... \& Vohs, K. D. (2014). Free will and punishment: A mechanistic view of human nature reduces retribution. Psychological Science, 25(8), 1563-1570. https://doi.org/10.1177/0956797614534693

Starmans, C., \& Bloom, P. (2016). When the spirit is willing, but the flesh is weak: Developmental differences in judgments about inner moral conflict. Psychological Science, 27(11), 1498-1506. https://doi.org/10.1177/0956797616665813 


\section{SELF-CONTROL AND MORALIZATION OF MENTAL STATES}

Szczurek, L., Monin, B., \& Gross, J. J. (2012). The stranger effect: The rejection of affective deviants. Psychological Science, 23(10), 1105-1111. https://doi.org/10.1177/0956797612445314

Tangney, J. P., Baumeister, R. F., \& Boone, A. L. (2004). High self-control predicts good adjustment, less pathology, better grades, and interpersonal success. Journal of Personality, 72(2), 271-324. https://doi.org/10.1111/j.0022-3506.2004.00263.x

Tittle, C. R., Ward, D. A., \& Grasmick, H. G. (2003). Self-control and crime/deviance: Cognitive vs. behavioral measures. Journal of Quantitative Criminology, 19(4), 333-365. https://doi.org/10.1023/B:JOQC.0000005439.45614.24

Uhlmann, E. L., Pizarro, D. A., \& Diermeier, D. (2015). A person-centered approach to moral judgment. Perspectives on Psychological Science, 10(1), 72-81. https://doi.org/10.1177/1745691614556679

Van Boven, L., \& Loewenstein, G. (2003). Social projection of transient drive states. Personality and Social Psychology Bulletin, 29(9), 1159-1168.

https://doi.org/10.1177/0146167203254597

Vonasch, A. J., Clark, C. J., Lau, S., Vohs, K. D., \& Baumeister, R. F. (2017). Ordinary people associate addiction with loss of free will. Addictive Behaviors Reports, 5, 56-66. https://doi.org/10.1016/j.abrep.2017.01.002

Verdejo-García, A., Bechara, A., Recknor, E. C., \& Pérez-García, M. (2007). Negative emotiondriven impulsivity predicts substance dependence problems. Drug and Alcohol Dependence, 91(2-3), 213-219. https://doi.org/10.1016/j.drugalcdep.2007.05.025 
SELF-CONTROL AND MORALIZATION OF MENTAL STATES

Vohs, K. D., \& Schooler, J. W. (2008). The value of believing in free will: Encouraging a belief in determinism increases cheating. Psychological Science, 19(1), 49-54. https://doi.org/10.1111/j.1467-9280.2008.02045.x

Voiklis, J., \& Malle, B. F. (2017). Moral cognition and its basis in social cognition and social regulation. In K. J. Gray \& J. Graham (Eds.), Atlas of moral psychology (pp. 108-120). Guilford Press.

Weiss, A., Burgmer, P., \& Mussweiler, T. (2018). Two-faced morality: Distrust promotes divergent moral standards for the self versus others. Personality and Social Psychology Bulletin, 44(12), 1712-1724. https://doi.org/10.1177/0146167218775693

Xiao, E., \& Houser, D. (2005). Emotion expression in human punishment behavior. Proceedings of the National Academy of Sciences, 102(20), 7398-7401. https://doi.org/10.1073/pnas.0502399102

Young, L., \& Saxe, R. (2011). When ignorance is no excuse: Different roles for intent across moral domains. Cognition, 120(2), 202-214. https://doi.org/10.1016/j.cognition.2011.04.005

Young, L., \& Tsoi, L. (2013). When mental states matter, when they don't, and what that means for morality. Social and Personality Psychology Compass, 7(8), 585-604. https://doi.org/10.1111/spc3.12044

Yuan, K. H., \& Bentler, P. M. (2000). 5. Three likelihood-based methods for mean and covariance structure analysis with nonnormal missing data. Sociological Methodology, 30(1), 165-200. https://doi.org/10.1111\%2F0081-1750.00078 


\section{Appendix A}

Self-Control Scale (Tangney, Baumeister, \& Boone, 2004; scale: $1=$ not at all to $5=$ very much)

Instruction: Using the scale provided, please indicate how much each of the following statements reflects how you typically are.

1. I am good at resisting temptation.

2. I have a hard time breaking bad habits.

3. I am lazy.

4. I say inappropriate things.

5. I never allow myself to lose control.

6. I do certain things that are bad for me, if they are fun.

7. People can count on me to keep on schedule.

8. Getting up in the morning is hard for me.

9. I have trouble saying no.

10. I change my mind fairly often.

11. I blurt out whatever is on my mind.

12. People would describe me as impulsive.

13. I refuse things that are bad for me.

14. I spend too much money.

15. I keep everything neat.

16. I am self-indulgent at times.

17. I wish I had more self-discipline.

18. I am reliable.

19. I get carried away by my feelings.

20. I do many things on the spur of the moment.

21. I don't keep secrets very well.

22. People would say that I have iron self- discipline.

23. I have worked or studied all night at the last minute.

24. I'm not easily discouraged.

25 . I'd be better off if I stopped to think before acting.

26. I engage in healthy practices.

27. I eat healthy foods.

28. Pleasure and fun sometimes keep me from getting work done.

29. I have trouble concentrating.

30. I am able to work effectively toward long-term goals.

31. Sometimes I can't stop myself from doing something, even if I know it is wrong.

32. I often act without thinking through all the alternatives.

33. I lose my temper too easily.

34. I often interrupt people.

35. I sometimes drink or use drugs to excess.

36. I am always on time. 


\section{Affair Scenario:}

\section{Situation Description: Mr. B.}

Mr. B. is a 2005 graduate of a University. He graduated with a 3.6 GPA with a BA in English and a minor in Communications. Since graduation, Mr. B. has worked at an entry-level job in a marketing firm. Mr. B. married his University sweetheart six months after they both had their graduation from University. Mr. B. and his wife do not have any children.

One of Mr. B.'s colleagues at work is a very attractive woman. This woman sometimes flirts with Mr. B. and they both know that she would be willing to have a sexual affair with him. Sometimes, Mr. B. consciously entertains thoughts about having a sexual affair with his colleague, thinking about where they would have an affair and what it would be like to have an affair with her.

\section{Moralization items:}

- How does it affect your judgment of Mr. B.'s character to know that Mr. B. consciously entertains thoughts about having a sexual affair with his colleague? $(1=$ very negatively, $7=$ very positively)

- My gut reaction is that Mr. B.'s consciously entertaining thoughts about having a sexual affair with his colleague is wrong. ( $1=$ strongly disagree, $7=$ strongly agree $)$

- Even if Mr. B. does not have a sexual affair with his colleague, he will probably be a bad person in other ways. $(1=$ strongly disagree, 7 = strongly agree $)$

Likelihood item (scale: 1 = very unlikely, 7 = very likely):

- How likely do you think Mr. B. is to have a sexual affair with his colleague?

Control ascriptions item (scale: 1 = completely involuntary, 7 = completely voluntary):

- How much control do you think Mr. B. has over his consciously entertaining thoughts about having a sexual affair with his colleague? In other words, are his thoughts involuntary, or do they result from voluntary effort?

General moralization of mental states items (scale: 1 = strongly disagree, 7 = strongly agree):

- A feature of immoral people is that they consciously entertain thoughts about doing immoral things.

- Being a moral person is more a matter of what is in your heart rather than what you do.

- The thoughts that a person consciously entertains are an important part of a person's character.

- Consciously entertaining thoughts about doing something immoral is as bad as doing it. 


\section{Appendix B}

\section{Affair Scenario:}

\section{Situation Description: Mr. B.}

Mr. B. is a 2005 graduate of a University. He graduated with a 3.6 GPA with a BA in English and a minor in Communications. Since graduation, Mr. B. has worked at an entry-level job in a marketing firm. Mr. B. married his University sweetheart six months after they both had their graduation from University. Mr. B. and his wife do not have any children.

Mr. B. has never cheated on his wife by having an affair with someone else. For years, Mr. B. has followed the career of the actress Natalie Portman with great interest, and he has always found her to be extremely attractive. Although Mr. B. knows that he will never meet Natalie Portman, he often fantasizes about her. At on average four times a week for on average 10 minutes, Mr. B. consciously entertains thoughts about having a sexual affair with Natalie Portman, thinking about where they would have an affair and what it would be like to have an affair with her.

Moralization items (scale: 1 = strongly disagree, 7 = strongly agree):

- It is perfectly normal for Mr. B. to fantasize about having an affair with Natalie Portman.

- How does it affect your judgment of Mr. B.'s character to know that Mr. B. consciously entertains thoughts about having a sexual affair with Natalie Portman?

- My gut reaction is that Mr. B.'s consciously entertaining thoughts about having a sexual affair with Natalie Portman is wrong.

- Mr. B. is a bad person.

- Thinking about having an affair with a person you will never meet is harmless.

Control ascriptions item (scale: 1 = completely involuntary, 7 = completely voluntary):

- How much control do you think Mr. B. has over his consciously entertaining thoughts about having a sexual affair with Natalie Portman? In other words, are his thoughts involuntary, or do they result from voluntary effort?

General moralization item (scale: 1 = completely involuntary, 7 = completely voluntary):

- Consciously entertaining thoughts about doing something immoral is as bad as doing it.

Behavior condemnation item (scale: 1 = very negatively, 7 = very positively):

- How would it affect your judgment of a person's character to know that they actually did have a sexual affair? 
Brief Self-Control Scale (Tangney, Baumeister, \& Boone, 2004; scale: $1=$ not at all, $5=$ very much):

1. I am good at resisting temptation.

2. I have a hard time breaking bad habits.

3. I am lazy.

4. I say inappropriate things.

5. I do certain things that are bad for me, if they are fun.

6. I refuse things that are bad for me.

7. I wish I had more self-discipline.

8. People would say that I have iron self-discipline.

9. Pleasure and fun sometimes keep me from getting work done.

10. I have trouble concentrating.

11. I am able to work effectively toward long-term goals.

12. Sometimes I can't stop myself from doing something, even if I know it is wrong.

13. I often act without thinking through all the alternatives. 


\section{Appendix C}

\section{Scientists Scenario:}

\section{Situation Description:}

Christopher and Alan are biology scientists at a university. They investigate in the same domain, a stem of non-hazardous tropical bacteria, and are at about the same career level. Christopher does not like Alan, and resents him his recent successes.

Even though Christopher does not have access to the laboratory where Alan works, because the two belong to different departments, Christopher sometimes fantasizes about destroying all of the special experimental cultures in Alan's lab. He takes pleasure in thinking how Alan would have to create all cell cultures anew in cumbersome evening hours.

Moralization items (scale: 1 = strongly disagree, 7 = strongly agree):

- It is morally wrong for Christopher to fantasize about destroying Alan's experimental cultures.

- It is perfectly okay for Christopher to fantasize about destroying Alan's experimental cultures.

- My gut reaction is that Christopher's fantasizing about destroying Alan's experimental cultures is wrong.

- Christopher is an immoral person.

- Christopher has bad character.

- Deep down, Christopher is good-natured.

Control ascriptions items (scale: 1 = strongly disagree, 7 = strongly agree):

- Christopher's entertaining thoughts about destroying Alan's experimental cultures is completely involuntary.

- Christopher's fantasies about destroying Alan's experimental cultures result from voluntary effort.

Behavior condemnation items (scale: $1=$ extremely immoral/very negatively, $7=$ very moral, extremely positively):

- What would you think if Christopher by accident had access to Alan's office and destroyed Alan's experimental cultures?

- What would you think if Christopher did something else to harm Alan's work?

- How would it affect your judgment of a person's character to know that he/she actually sabotaged a colleague's work out of dislike and resentment? 
SELF-CONTROL AND MORALIZATION OF MENTAL STATES

\section{Appendix D}

Control ascriptions items (scale: $1=$ strongly disagree, $7=$ strongly agree). Items were preceded by the Scientists Scenario and followed by the moralization items from Study 2a (see APPENDIX C):

- Christopher freely chooses to fantasize about destroying Alan's experimental cultures.

- Christopher's thoughts about destroying Alan's experimental cultures are intentional.

- Christopher could prevent his fantasies about destroying Alan's experimental cultures, if he wanted.

- Christopher is capable of choosing his thoughts about destroying Alan's experimental cultures.

- Christopher experiences a compelling urge to think about destroying Alan's experimental cultures.

- Christopher wants to fantasize about destroying Alan's experimental cultures. 


\section{Appendix E}

Emotion Regulation Questionnaire (Gross \& John, 2003; scale: 1 = not true at all, 7 = completely true)

- When I want to feel more positive emotion (such as joy or amusement), I change what I'm thinking about. (R)

- I keep my emotions to myself. (S)

- When I want to feel less negative emotion (such as sadness or anger), I change what I'm thinking about. (R)

- When I am feeling positive emotions, I am careful not to express them. (S)

- When I'm faced with a stressful situation, I make myself think about it in a way that helps me stay calm. (R)

- I control my emotions by not expressing them. (S)

- When I want to feel more positive emotion, I change the way I'm thinking about the situation. (R)

- I control my emotions by changing the way I think about the situation I'm in. (R)

- When I am feeling negative emotions, I make sure not to express them. (S)

- When I want to feel less negative emotion, I change the way I'm thinking about the situation. $(\mathrm{R})$

( $\mathrm{R}$ = reappraisal factor; $\mathrm{S}=$ suppression factor; German translation by Abler \& Kessler, 2009)

Scenarios (scale: 1 = not at all, 7 = completely; English translation; for German version, please see https://osf.io/2tp5j/?view_only=19f72ff695fc4f66ab394a6c484244ea)

\section{Romantic Rival Scenario}

1. A couple of months after their breakup, Richard's ex girlfriend already found a new boyfriend at the gym. Richard is jealous and furious at him.

- Richard could control his fury and jealousy of the new partner, if he wanted to.

\section{Study Scenario}

2. Pascal, who did not apply for the same Master's program, is very envious of Max, who was admitted to a Master's program at a prestigious university. He imagines Max failing his studies.

- Pascal could change his being envious of Max, if he wanted to. 


\section{Host Scenario}

3. Sarah is invited to a party. She does not want to go to this party because she may run into a colleague whom she does not like very much. Shortly before the party, she learns that the host has fallen sick. Sarah hopes that the host's illness will worsen so that she does not have to actively cancel her attendance or actually go to the party.

- Sarah could change her hoping that the host's illness would worsen, if she wanted to.

\section{Grade Scenario}

4. Elena received a poor grade for an exam for which she did not study very hard. Now Elena is mad at the lecturer who created the exam and blames her for her poor grade.

- Elena could change her being angry at the lecturer, if she wanted to.

\section{Cat Scenario}

5. Jens's flat mate's cat often dirties up their common living room, and Jens is very annoyed by this. Over the past weeks, the cat seemed to not do so well. When his flat mate takes the cat to the vet one day, Jens imagines what it would be like if the cat died and did not live in the flat any more.

- Jens could change his imagination about his flat mate's cat dying, if he wanted to.

\section{Breakup Scenario}

6. Christina learns that a fellow student was left by her boyfriend and that she is very sad now. Christina, who does not like this fellow student, is happy about that.

- Christina could change her being happy about her fellow student having been left by her boyfriend, if she wanted to. 


\section{Appendix F}

Mind-Wandering Questionnaire (adapted from Schubert et al., 2020; scale: 1 = almost never/do not agree, 7 = almost always/completely agree; English translation; for German items, please see https://osf.io/2tp5j/?view_only=19f72ff695fc4f66ab394a6c484244ea)

- I have difficulty maintaining focus on simple or repetitive tasks. (MWQ)

- While reading, I find I haven't been thinking about the text and must therefore read it again. (MWQ)

- I do things without paying full attention. (MWQ)

- I find myself listening with one ear, thinking about something else at the same time. (MWQ)

- I mind-wander during lectures. (adapted from MWQ)

- I allow my thoughts to wander on purpose. (MW-D)

- I enjoy mind-wandering. (MW-D)

- I find mind-wandering is a good way to cope with boredom. (MW-D)

- I allow myself to get absorbed in pleasant fantasy. (MW-D)

- I find my thoughts wandering spontaneously. (MW-S)

- When I mind-wander my thoughts tend to be pulled from topic to topic. (MW-S)

- It feels like I don't have control over when my mind wanders. (MW-S)

- I mind wander even when I'm supposed to be doing something else. (MW-S)

MWQ: Mind-Wandering Questionnaire, Mrazek et al., 2013

MW-S: Mind-Wandering Spontaneous Subscale, Carriere et al., 2013

MW-D: Mind-Wandering Deliberate Subscale, Carriere et al., 2013 


\section{Appendix G}

Below, stimulus materials of Study 2 a are listed. Manipulation check items were presented identically in both conditions.

\section{High-control condition}

Autobiographical Experiences: Emotional Control

Please recall two situations from your own life when you found it easy to control your emotions. By that, we mean a situation where you feel that you sucessfully managed, changed, or controlled your emotions.

You might recall a situation when you managed to not get carried away by your emotions. Similarly, you might recall a time when you had no or not much trouble distracting yourself from or changing your feelings about, and your emotional reactions to a situation.

Please recall these situations in as much detail as possible, and describe each of them in a few sentences. How did you feel? In what matter did you manage to control or change your emotions?

\section{Low-control condition}

Autobiographical Experiences: Emotional Control

Please recall two situations from your own life when you found it difficult to control your emotions. By that, we mean a situation where you feel that you did not, or experienced difficulties, to sucessfully manage, change, or controll your emotions.

You might recall a situation when you got carried away by your emotions. Similarly, you might recall a time when you had trouble distracting yourself from or changing your feelings about, and your emotional reactions to a situation.

Please recall these situations in as much detail as possible, and describe each of them in a few sentences. How did you feel? In what matter did you find it difficult to control or change your emotions?

Please answer the below questions about the situations you just described: During the situations I recalled, ...

- ... I had little control over my emotions.

- ... I experienced difficulties to manage my emotional reactions.

- ... I got carried away by my emotions. 
SELF-CONTROL AND MORALIZATION OF MENTAL STATES

(scales: $1=$ not at all, $9=$ very much)

Scenarios (scales for all scenario items: $1=$ completely disagree, $9=$ completely agree; Scenario names (i.e., the headings) were not presented to participants.)

\section{Surgery Scenario}

Brian is a 34-year old man who recently had a leg surgery that required removing some healthy leg tissue to prevent an inflammation. During his stay in the hospital, which he does not like, Brian has thoughts about harming other people, such as the nurses and doctors.

- Brian is fully capable of choosing his thoughts about harming the hospital personnel.

- Brian's thoughts about harming other people are intentional.

\section{Scientists Scenario}

Christopher and Alan are biology scientists at a university. They investigate in the same domain, a stem of non-hazardous tropical bacteria, and are at about the same career level. Christopher does not like Alan, and resents him his recent successes.

One day, while he is in the office and has nothing to do, Christopher imagines destroying all of Alan's experimental cultures.

- Christopher is fully capable of choosing his thoughts about destroying Alan's experimental cultures.

- Christopher's thinking of destroying Alan's experimental cultures is intentional.

\section{Jealousy Scenario}

Gina and her husband Steve have been married for a couple of years. A few months ago, Mike moved next door in their small neighborhood. Gina and Steve both like Mike and become friends with him. However, after a while, Gina becomes annoyed by Mike's presence.

When Steve and Mike hang out, Gina sometimes becomes extremely jealous, and she wishes that Mike would move away again. She wishes he would lose his job, so that he won't be able to afford his house any longer.

- Gina is fully capable of choosing her wishing that Mike should lose his job.

- Gina's wishing that Mike would lose his job is intentional. 


\section{Thriller Scenario}

Erica is a journalist. She has recently joined a new team. One night after work, she goes to the movies to see a thriller with her boyfriend. In one scene, a central figure of this movie is severely beaten up, and Erica imagines it was her new boss, who is being beaten.

- Erica is is fully capable of choosing her thoughts of her boss being beaten.

- Erica's imagining her boss being beaten is intentional.

\section{Affair Scenario}

John is a 42-year old man, who has been married to his high school sweetheart for many years. John sometimes fantasizes about having an affair with actress Natalie Portman.

- John is fully capable of choosing his thoughts about having an affair with Natalie Portman.

- John's fantasizing about an affair with Natalie Portman is intentional. 


\section{Appendix H}

Below, high-control versions and low-control versions of each scenario are listed. Items are listed only once, as these were identical for both versions. Scenario names (i.e., headings) were not presented to participants.

\section{Surgery Scenario - high-control version}

Brian is a 34-year old man who recently had a leg surgery that required removing some healthy leg tissue to prevent an inflammation. As a result, his motor control is impaired.

During his stay in the hospital, which he does not like, Brian has thoughts about harming other people, such as the nurses and doctors. Brian actively produces these thoughts, and he could suppress them, if he wanted.

\section{Surgery Scenario - low-control version}

Brian is a 34-year old man who recently had brain surgery that required removing some healthy brain tissue to prevent an inflammation. As a result, his thought control is impaired.

During his stay in the hospital, which he does not like, Brain has intrusive thoughts about harming other people, such as the nurses and doctors. These thoughts sometimes simply pop into his head, and due to his condition, he can't do anything to supress them.

- It is morally wrong for Brian to think about harming other people.

- Brian deserves blame for thinking about harming other people.

\section{Thriller Scenario - high-control version}

Erica is a journalist. She has recently joined a new team. One night after work, she goes to the movies to see a thriller with her boyfriend.

In one scene, a central figure of this movie is severely beaten up, and even though he does not resemble her boss at all, Erica imagines it was her new boss, who is being beaten.

\section{Thriller Scenario - low-control version}

Erica is a journalist. She has recently joined a new team. One night after work, she goes to the movies to see a thriller with her boyfriend.

One central figure of this movie very strongly resembles her new boss. In one scene, this character is severely beaten up, and Erica imagines it was her new boss, who is being beaten.

- It is morally wrong for Erica to imagine that her boss were the character in the movie who is beaten up. 
- Erica deserves blame for imagining that her boss were the character in the movie who is beaten up.

\section{Jealousy Scenario - high-control version}

Gina and her husband Steve have been married for a couple of years. A few months ago, Mike moved next door in their small neighborhood. Gina and Steve both like Mike and become friends with him. However, after a while, Gina becomes annoyed by Mike's presence.

In situations when Steve and Mike hang out, Gina sometimes becomes extremely jealous, and she wishes that Mike would move away again. She wishes he would lose his job, so that he won't be able to afford his house any longer.

\section{Jealousy scenario - low-control version}

Gina and her husband Steve have been married for a couple of years. A few months ago, Mike moved next door in their small neighborhood. Gina and Steve both like Mike and become friends with him. However, after a while, Gina becomes annoyed by Mike's presence. Gina has a personality disorder. Patients with this this disorder are very dependent on close others, are often overwhelmed by their emotions, and have difficulties regulating them.

In situations when Steve and Mike hang out, Gina sometimes becomes extremely jealous, and she wishes that Mike would move away again. She wishes he would lose his job, so that he won't be able to afford his house any longer.

- It is morally wrong for Gina to wish that Mike would lose his job.

- Gina deserves blame for wishing that Mike would lose his job.

\section{Scientists Scenario - high-control version}

Christopher and Alan are biology scientists at a university. They investigate in the same domain, a stem of non-hazardous tropical bacteria, and are at about the same career level. Christopher does not like Alan, and resents him his recent successes.

One day, while he is in the office and has nothing to do, Christopher imagines destroying all of Alan's experimental cultures.

\section{Scientists Scenario - low-control version}

Christopher and Alan are biology scientists at a university. They investigate in the same domain, a stem of non-hazardous tropical bacteria, and are at about the same career level. Christopher does not like Alan, and resents him his recent successes. 
One night, in his dreams, Christopher imagines destroying all of Alan's experimental cultures.

- It is morally wrong for Christopher to imagine destroying Alan's experimental cultures.

- Christopher deserves blame for imagining destroying Alan's experimental cultures.

\section{Firewood Scenario - high-control version}

Aidan lives in a small town in a little house surrounded by other houses. Aidan is kind of a loner, and does not like to be around people much.

When he walks around the house to fetch firewood, he often imagines setting his neighbor's house on fire.

\section{Firewood Scenario - low-control version}

Aidan lives in a small town in a little house surrounded by other houses. Aidan is kind of a loner, and does not like to be around people much. Aidan has obsessive compulsive disorder. This means that he experiences compulsive thoughts that he cannot control.

When he walks around the house to fetch firewood, he often imagines setting his neighbor's house on fire.

- It is morally wrong for Aidan to imagine he would set fire to his neighbor's house.

- Aidan deserves blame for imagining he would set fire to his neighbor's house.

\section{Affair Scenario - high-control version}

John is a 42-year old man, who has been married to his high school sweetheart for many years. John sometimes fantasizes about having an affair with actress Natalie Portman.

His fantasies are deliberate and intentional, and he could suppress them, if he tried.

\section{Affair Scenario - low-control version}

John is a 42-year old man, who has been married to his high school sweetheart for many years. John sometimes fantasizes about having an affair with actress Natalie Portman.

These fantasies simply come into his mind, and he has no control over them.

- It is morally wrong for John to fantasize about having an affair with Natalie Portman.

- John deserves blame for fantasizing about having an affair with Natalie Portman. 
SELF-CONTROL AND MORALIZATION OF MENTAL STATES

\section{Appendix I. Supplementary data}

Research data for this article can be accessed at:

https://osf.io/2tp5j/?view_only=19f72ff695fc4f66ab394a6c484244ea 